\title{
Creation and Control of Two-Dimensional Electron Gas Using Al-Based Amorphous Oxides/SrTiO II_3V Heterostructures Grown by Atomic Layer Deposition
}

\section{Citation}

Lee, Sang Woon, Yiqun Liu, Jaeyeong Heo and Roy G. Gordon. 2012. Creation and control of twodimensional electron gas using Al-based amorphous oxides/SrTiOl__3V heterostructures grown by atomic layer deposition. Nano Letters 12(9): 4775-4783.

\section{Published Version}

doi: $10.1021 / \mathrm{nl} 302214 \mathrm{x}$

\section{Permanent link}

http://nrs.harvard.edu/urn-3:HUL.InstRepos:9716627

\section{Terms of Use}

This article was downloaded from Harvard University's DASH repository, and is made available under the terms and conditions applicable to Open Access Policy Articles, as set forth at http:// nrs.harvard.edu/urn-3:HUL.InstRepos:dash.current.terms-of-use\#OAP

\section{Share Your Story}

The Harvard community has made this article openly available.

Please share how this access benefits you. Submit a story.

\section{Accessibility}




\title{
Creation and Control of Two-Dimensional Electron Gas
}

\section{Using Al-Based Amorphous Oxides/SrTiO 3 Heterostructures}

\section{Grown by Atomic Layer Deposition}

\author{
Sang Woon Lee, ${ }^{\dagger}$ Yiqun Liu, ${ }^{\dagger, \dagger}$ Jaeyeong Heo, ${ }^{\dagger, \S}$ and Roy G. Gordon ${ }^{*}, \dagger$ \\ †Department of Chemistry and Chemical Biology, Harvard University, Cambridge,
}

Massachusetts 02138, United States

"GLOBALFOUNDARIES, Inc., Malta, New York 12020, United States

${ }^{\S}$ Department of Materials Science and Engineering, Chonnam National University, Gwangju, 500-757, Korea 


\section{ABSTRACT}

The formation of a two-dimensional electron gas (2-DEG) using $\mathrm{SrTiO}_{3}$ (STO)-based heterostructures provides promising opportunities in oxide electronics. We realized the formation of 2-DEG using several amorphous layers grown by the atomic layer deposition (ALD) technique at $300{ }^{\circ} \mathrm{C}$ which is a process compatible with mass production, and thereby can provide realization of potential applications. We found that the amorphous $\mathrm{LaAlO}_{3}(\mathrm{LAO})$ layers grown by the ALD process can generate 2-DEG $\left(\sim 1 \times 10^{13} / \mathrm{cm}^{2}\right)$ with an electron mobility of $4-5 \mathrm{~cm}^{2} / \mathrm{V} \cdot \mathrm{s}$. A much higher electron mobility was observed at lower temperatures. More remarkably, amorphous $\mathrm{YAlO}_{3}(\mathrm{YAO})$, and $\mathrm{Al}_{2} \mathrm{O}_{3}$ layers, which are not polar-perovskitestructured oxides, can create 2-DEG as well. 2-DEG was created by means of the important role of trimethylaluminum, $\mathrm{Me}_{3} \mathrm{Al}$, as a reducing agent for STO during LAO and YAO ALD as well as the $\mathrm{Al}_{2} \mathrm{O}_{3} \mathrm{ALD}$ process at $300{ }^{\circ} \mathrm{C}$. The deposited oxide layer also plays an essential role as a catalyst that enables $\mathrm{Me}_{3} \mathrm{Al}$ to reduce the STO. The electrons were localized very near to the STO surface, and the source of carriers was explained based on the oxygen vacancies generated in the STO substrate.

KEYWORDS: 2-D electron gas, amorphous, $\mathrm{LaAlO}_{3}, \mathrm{Al}_{2} \mathrm{O}_{3}, \mathrm{SrTiO}_{3}$, atomic layer deposition (ALD), oxygen vacancy 


\section{Table of Contents Summary}

Sang Woon Lee, Yiqun

Liu, Jaeyeong Heo, and

Roy G. Gordon

Creation and Control of

Two-Dimensional Electron

Gas Using Al-Based

Amorphous Oxides/SrTiO

Heterostructures Grown by

Atomic Layer Deposition

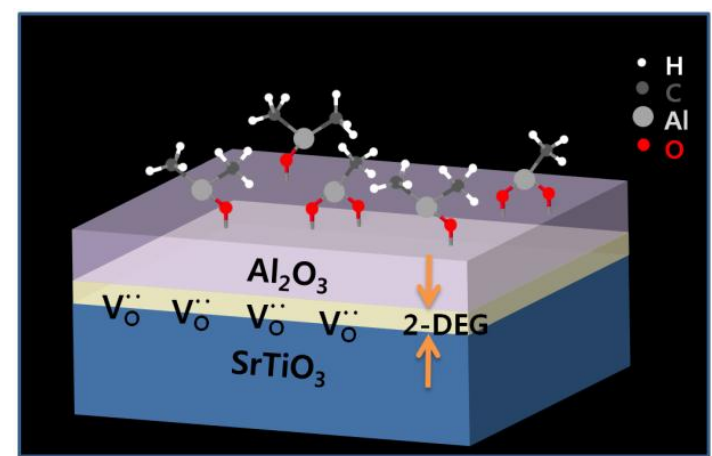

$\mathrm{SrTiO}_{3}$ 
Heterostructures between complex oxide layers are emerging as interesting systems for oxide electronics due to their unique properties. ${ }^{1}$ Ohtomo reported the existence of a 2 dimensional electron gas (2-DEG) at the heterointerface between the two insulating oxides $\mathrm{LaAlO}_{3}$ (lanthanum aluminate, LAO) and $\mathrm{SrTiO}_{3}$ (strontium titanate, STO). ${ }^{2}$ The LAO films were grown by pulsed laser deposition (PLD) or molecular beam epitaxy (MBE) on a single crystalline (001) STO substrate. ${ }^{2-8}$ Transistor-like devices using these LAO/STO heterostructures have also been demonstrated. ${ }^{3}$ The most common explanation of the observation of 2-DEG at the LAO/STO interface was based on electronic reconstruction, where the electrons move to the interface to avoid the potential divergence caused by the polar catastrophe. ${ }^{9}$ The interface charges are compensated by $\mathrm{Ti}^{3+}$ ions that provide electrons to the STO conduction band, and these interface electrons are localized near the $\mathrm{AlO}_{2} / \mathrm{LaO} / \mathrm{TiO}{ }_{2}$ interface, which is called an n-type interface. Basically, this electronic reconstruction can only be realized at a well-prepared abrupt and sharp epitaxial interface between single crystalline LAO and STO. An alternative explanation for the generation of 2-DEG is La inter-diffusion through the interface, doping the surface layer of the STO to be n-type. ${ }^{10} \mathrm{~A}$ third explanation is defect generation such as oxygen vacancies in the STO substrate. ${ }^{10-12}$ Recently, it has been discussed that the oxygen vacancies can be generated at the STO substrate during the growth 
of the LAO layer as the possible origin of the carrier source. ${ }^{13,14}$ In the meantime, the formation of oxygen vacancies has been also supported by theoretical first-principle calculations. ${ }^{15,16}$

Strontium titanate is well-known as a high- $k$ dielectric (bulk dielectric constant of 300) with a bandgap of $3.2 \mathrm{eV}$ which has been extensively studied for possible use in electronic devices such as dynamic random access memory (DRAM). Strontium titanate has a cubic perovskite structure with a lattice constant of $0.3905 \mathrm{~nm}$. Lanthanum aluminate is a wide bandgap insulator $(5.6 \mathrm{eV})$ which has a quasi-cubic structure with a lattice constant of 0.3789 $\mathrm{nm}$; thus the lattice mismatch between STO and LAO is small $(\sim 3 \%){ }^{2}$

Up to now, epitaxially grown LAO films have been necessary for the creation of 2DEG. The epitaxial LAO films were grown on an STO substrate by the PLD process at a relatively high growth temperature $\left(650 \sim 850{ }^{\circ} \mathrm{C}\right)^{2-7,9,11-14,17-20}$ which is one of the representative physical vapor deposition (PVD) techniques. However, the feasibility of an amorphous layer is rarely reported, except in a recent study using amorphous layers grown by the PLD process at room temperature. ${ }^{13}$ Unfortunately, the PLD process has a lower chance of being used in mass production of devices.

ALD is characterized by its unique self-limiting growth mechanism based on alternating saturated surface reactions. The precursor and oxygen source are pulsed into a reactor alternately, and each injection is separated by a purging process using inert gas. ${ }^{21}$ This 
process provides a lot of advantages in terms of excellent conformality and precise control of thickness as well as large area uniformity. In practice, the ALD process is being widely used for the growth of dielectric films in the mass-production of microelectronic devices. ${ }^{21}$

In this paper, a practical, novel technique is proposed to create and control 2-DEG using several amorphous films on STO substrates in which oxygen vacancies act as the source of the carriers. An amorphous LAO layer grown by an ALD process creates 2-DEG by generating oxygen vacancies in the STO substrate. More remarkably, amorphous $\mathrm{Al}_{2} \mathrm{O}_{3}$ as well as $\mathrm{YAlO}_{3}$ (YAO) grown by ALD on STO substrates, which are not polar-perovskite structured oxides, can create 2-DEG at the interface. The aluminum source for these ALD processes, trimethylaluminum (TMA), creates oxygen vacancies in the STO substrate during the growth of several aluminum-containing layers, including amorphous LAO, YAO and $\mathrm{Al}_{2} \mathrm{O}_{3}$. However, treatment with TMA vapor alone does not create any oxygen vacancies. The presence of a growing oxide layer ( $\mathrm{LAO}, \mathrm{Al}_{2} \mathrm{O}_{3}, \mathrm{YAlO}_{3}$, etc.) produced by water vapor as a co-reactant is also needed to catalyze the reduction. 2-DEG density was controlled precisely and reproducibly, which indicates that the formation of oxygen vacancies was well-controlled by the ALD process. Growth of other oxides not containing $\mathrm{Al}$, such as $\mathrm{Y}_{2} \mathrm{O}_{3}, \mathrm{La}_{2} \mathrm{O}_{3}$, or $\mathrm{LaYO}_{3}$, did not produce 2-DEG. 
All films used in this experiment, including the LAO layer, were grown by ALD at 300

${ }^{\circ} \mathrm{C}$. The ALD technique enabled the formation of smooth and high quality oxide thin films at a low growth temperature $\left(300{ }^{\circ} \mathrm{C}\right)$ with atomic precision, which is essential to the functionality of oxide heterostructures. The $\mathrm{Al}_{2} \mathrm{O}_{3}$ ALD process offers great advantages in terms of massproduction compatibility due to its ideal ALD reaction. ${ }^{22}$ The growth of an amorphous layer is easy to achieve by the ALD process with a large process margin; thus it is promising for the realization of potential applications.

\section{Results and Discussions}

Figure 1 (a) shows the cross sectional high-resolution transmission electron microscopy (TEM) image of the LAO layer grown by ALD at $300^{\circ} \mathrm{C}$ on an STO substrate. The amorphous LAO layer grown on a single crystalline STO substrate is clearly observed. Figure 1 (b) shows the [001] zone axis electron diffraction pattern at the interfacial region of the LAO/STO heterostructure. The diffraction pattern consists of single spots, and those diffraction spots are exactly consistent with those of single crystalline $\mathrm{STO}^{23}$, which indicates that the STO substrate used in this experiment is a perfect single crystalline material. However, no diffraction spots were observed from the LAO layer, which confirms the amorphous nature of the LAO layer. 
The surface morphologies of the samples were investigated by means of an atomic force microscope (AFM). Figure 2 (a) shows the surface morphology of a $\mathrm{TiO}_{2}$-terminated STO substrate. ${ }^{24,25}$ The surface consists of regular terrace structures with a high smoothness (rms roughness of $0.15 \mathrm{~nm}$ ). The height difference between the adjacent terraces is about $0.4 \mathrm{~nm}$ which corresponds to one unit-cell of STO as shown in Fig. 2 (b). Figure 2 (c) shows the surface morphology of a $6 \mathrm{~nm}$ thick LAO film grown on an STO substrate by the ALD process at 300 ${ }^{\circ} \mathrm{C}$. The roughness of the LAO surface (about $0.2 \mathrm{~nm}$ ) is slightly higher than that of the STO substrate. The background terrace structure was preserved although the LAO film was grown on an STO substrate. This result implies that LAO films grown by ALD are very smooth, replicating the underlying terrace structure. Figure 2 (d) shows the sheet resistance $\left(R_{\mathrm{s}}\right)$ and sheet carrier density $\left(\mathrm{n}_{\mathrm{s}}\right)$ as a function of the amorphous LAO film thickness grown on the STO substrate (LAO/STO heterostructure). A stoichiometric (51.4 at. \% of La) LAO film was grown by an ALD cycle ratio of 2:1 (La:Al) as confirmed by RBS (Fig. S1 (a)), and the thicknesses of the films grown on the STO substrate were estimated by an X-ray reflectivity (XRR) measurement (Fig. S2). Even with amorphous LAO films, the carriers can be created and a critical thickness exists which is required to make the channel to be conducting. The insulating interface of the LAO/STO heterostructures becomes conducting above a LAO thickness of $\sim 3$ $\mathrm{nm}$, and the sheet resistance and sheet carrier density remain constant above this critical 
thickness. Here, the type of carrier is an electron according to the sign of the Hall voltage. This transition behavior of the amorphous LAO/STO heterostructure is similar to the epitaxial LAO/STO heterostructure. ${ }^{3,6}$ The critical thickness of $\sim 3 \mathrm{~nm}$ is somewhat thicker than the commonly reported value ( 4 unit cells) from the epitaxial LAO films grown by PLD. ${ }^{3}$ The sheet resistance and sheet carrier density of the amorphous LAO/STO heterostructures were $\sim 1 \times 10^{5} \Omega / \mathrm{sq}$. and $\sim 1 \times 10^{13} / \mathrm{cm}^{2}$, respectively, where the mobility was $4 \sim 5 \mathrm{~cm}^{2} / \mathrm{V} \cdot \mathrm{s}$ as shown in Fig. 2 (e), whereas those of the insulating heterostructures were $>10^{9} \Omega /$ sq. and $<10^{9} / \mathrm{cm}^{2}$ which are beyond the sensitivity of the measurement.

Astonishingly, the 2-DEG can be generated by depositing an amorphous $\mathrm{Al}_{2} \mathrm{O}_{3}$ layer as well as a YAO layer on the STO substrate as shown in Fig. 3. Figure 3 (a) shows the schematic diagram of several heterostructures using various oxide layers. The sheet resistance and carrier density of the YAO/STO heterostructure were almost identical with those of the LAO/STO heterostructure as shown in Fig. 3 (b). The sheet resistance of the $\mathrm{Al}_{2} \mathrm{O}_{3} / \mathrm{STO}$ heterostructure is slightly higher than that of the STO/LAO heterostructure by a factor of 3 because of the reduced carrier density $\left(\sim 3 \times 10^{12} / \mathrm{cm}^{2}\right)$. However, the 2-DEG was not generated by depositing amorphous $\mathrm{La}_{2} \mathrm{O}_{3}, \mathrm{Y}_{2} \mathrm{O}_{3}$ or $\mathrm{LaYO}_{3}(\mathrm{LYO})$ layers on an STO substrate at $300{ }^{\circ} \mathrm{C}$ by ALD as shown in Fig. 3 (b). The basic crystal structure of YAO is an orthorhombic, a space group $\mathrm{P}_{\mathrm{nma}}$ (space group number 62), which lattice constants are: $\mathrm{a}=0.5330 \mathrm{~nm}, \mathrm{~b}=0.7375 \mathrm{~nm}$, and $\mathrm{c}=0.5180 \mathrm{~nm} .{ }^{26}$ 
This is a small distortion of the perovskite unit cell. However, it should be noted that $\mathrm{Al}_{2} \mathrm{O}_{3}$ is not a polar-perovskite structured oxide with cubic or distorted cubic unit cells. Instead, crystalline $\mathrm{Al}_{2} \mathrm{O}_{3}$ can be described by trigonal or hexagonal unit cells (space group number 167), while $\mathrm{ALD}_{2} \mathrm{O}_{3}$ is amorphous.

Figure 4 (a) shows the sheet resistance and sheet carrier density of an $\mathrm{Al}_{2} \mathrm{O}_{3} / \mathrm{STO}$ heterostructure as a function of $\mathrm{Al}_{2} \mathrm{O}_{3}$ film thickness when $\mathrm{Al}_{2} \mathrm{O}_{3}$ is grown on a STO substrate. The sheet resistance decreased sharply, and the sheet carrier density increased abruptly above an $\mathrm{Al}_{2} \mathrm{O}_{3}$ thickness of $1.2 \mathrm{~nm}$. Then the sheet resistance and sheet carrier density remained constant above this critical thickness. The sheet resistance and sheet carrier density of the conducting heterostructure are $4 \times 10^{5} \Omega / \mathrm{sq}$. and $\sim 3 \times 10^{12} / \mathrm{cm}^{2}$, respectively. The carrier density of the $\mathrm{Al}_{2} \mathrm{O}_{3} / \mathrm{STO}$ heterostructure is slightly lower than that of the LAO/STO heterostructure $\left(\sim 1 \times 10^{13} / \mathrm{cm}^{2}\right)$ as mentioned earlier. The mobility was constant regardless of the $\mathrm{Al}_{2} \mathrm{O}_{3}$ film thickness (Fig. S3 (a)).

Figure 4 (b) shows the sheet resistance and sheet carrier density of the $\mathrm{LAO} / \mathrm{Al}_{2} \mathrm{O}_{3} / \mathrm{STO}$ heterostructure as a function of $\mathrm{Al}_{2} \mathrm{O}_{3}$ film thickness when the $\mathrm{Al}_{2} \mathrm{O}_{3}$ film was grown prior to the growth of the LAO film. Six nm-thick LAO films were grown on top of $\mathrm{Al}_{2} \mathrm{O}_{3}$ films to fabricate the $\mathrm{LAO} / \mathrm{Al}_{2} \mathrm{O}_{3} / \mathrm{STO}$ heterostructures. The sheet resistance and created carrier density of the $\mathrm{LAO} / \mathrm{Al}_{2} \mathrm{O}_{3} / \mathrm{STO}$ heterostructure were identical to those of the $\mathrm{Al}_{2} \mathrm{O}_{3} / \mathrm{STO}$ 
heterostructure, which suggests the creation of the 2-DEG was determined by the $\mathrm{Al}_{2} \mathrm{O}_{3}$ layer, not by the LAO layer. The mobility was constant irrespective of the $\mathrm{Al}_{2} \mathrm{O}_{3}$ film thickness (Fig. S3 (a)).

Figure 4 (c) shows the sheet resistance and sheet carrier density of the YAO/STO heterostructure as a function of YAO film thickness. The stoichiometric (51.3 at. \% of Y) YAO film was grown by an ALD cycle ratio (Y:Al) of 2:1 as confirmed by Rutherford backscattering spectroscopy (RBS) (Fig. S1 (b)). The transition behaviors of the resistance, carrier density and mobility depending on the film thickness are almost identical with the LAO/STO heterostructure as shown in Fig. 2 (d). However, the insulating interface of the YAO/STO heterostructure becomes conducting above a YAO thickness of $\sim 4 \mathrm{~nm}$. The critical thickness of $\sim 4 \mathrm{~nm}$ for $\mathrm{YAO}$ is thicker than that of the $\mathrm{LAO} / \mathrm{STO}$ heterostructure.

All these layers are amorphous as confirmed by TEM and X-ray diffraction (XRD) (Fig. S4), so the polar catastrophe mechanism can be ruled out as the explanation for the formation of 2-DEG in our heterostructures. The possibility of a La ion doping into the STO substrate was ruled out because the 2-DEG was not generated when the single layer of $\mathrm{La}_{2} \mathrm{O}_{3}$ was grown on the STO substrate. It has been reported that La atoms can replace Sr sites in STO to generate electrons by $\mathrm{La}_{\mathrm{Sr}}$ substitution; ${ }^{27,28}$ however, this phenomenon was not observed in this work. The possibility of an Al ion doping into the STO substrate can also be excluded 
because it is known that $\mathrm{Al}$ atoms are prone to replace $\mathrm{Ti}$ sites, where $\mathrm{Al}$ atoms can act as acceptors. ${ }^{29-31}$ The substituted $\mathrm{Al}$ atoms in Ti sites reduce the density of electrons, so that the $\mathrm{Al}$ doping technique has been used to reduce the carriers in $\mathrm{TiO}_{2}$-based dielectric materials. The chance of a Y ion doping into the STO substrate was also excluded, as well as La ion doping, for the same reason.

The likely origin of the free electrons is the creation of oxygen vacancies in the STO during the growth of aluminum-containing oxides such as LAO, YAO and $\mathrm{Al}_{2} \mathrm{O}_{3}$. The possibility of reduction of the STO substrate prior to the deposition of each film can be excluded. It has been reported that the STO substrate is reduced at a growth temperature of 800 ${ }^{\circ} \mathrm{C}$ and low oxygen pressure of $10^{-6}$ mbar without the actual deposition of an LAO film grown by PLD due to high growth temperature and low oxygen pressure. ${ }^{14}$ Basically, the STO substrate used in our experiment is insulating $\left(\mathrm{R}_{\mathrm{s}}>10^{9} \Omega /\right.$ sq. $)$ before the deposition of the oxides, and the STO substrate still keeps its insulating property even in the chamber without actual growth of the film for a few hours. Also a STO substrate keeps its insulating property even after an exposure of the STO substrate to TMA molecules (see Fig. S6 and supporting information).

The observation of the $\mathrm{Ti}^{3+}$ binding state from the $\mathrm{Ti} 2 \mathrm{p}$ core-level spectrum can provide direct evidence of oxygen vacancies in the STO. X-ray photoelectron spectroscopy 
(XPS) measurements were performed in order to determine the valence state of $\mathrm{Ti}$ as shown in Fig. 5. Figure 5 (a) shows the normalized $\mathrm{Ti} 2 \mathrm{p}$ spectra of a 2.5 nm-thick $\mathrm{Al}_{2} \mathrm{O}_{3} / \mathrm{STO}$ heterostructure, and the signal from the bare STO substrate was used for comparison. An increased $\mathrm{Ti}^{3+}$ signal at $\sim 456.2 \mathrm{eV}$ was observed in the $\mathrm{Al}_{2} \mathrm{O}_{3} / \mathrm{STO}$ heterostructure compared to the bare STO substrate, which means that the oxygen vacancies were generated in the STO during the growth of the $\mathrm{Al}_{2} \mathrm{O}_{3}$ layer by $\mathrm{ALD}$. For the estimation of the $\mathrm{Ti}^{3+}$ depth profile, angle-resolved XPS was measured with various photoelectron take-off angles with a $2.5 \mathrm{~nm}$ thick $\mathrm{Al}_{2} \mathrm{O}_{3} / \mathrm{STO}$ heterostructure as shown in Fig. 5 (b). The effective electron escape depth decreases with decreasing the takeoff angle; thus the XPS spectrum becomes more surfacesensitive (Fig. S5). The signal of $\mathrm{Ti}^{3+}$ relative to the $\mathrm{Ti}^{4+}$ main line increases as the takeoff angle decreases. This indicates that the electrons generated by oxygen vacancies are localized at the STO surface region as a 2-DEG (within $\sim 2 \mathrm{~nm}$ from the interface), which is smaller than the electron escape depth ( $\sim 5 \mathrm{~nm}$, see Supporting Information).

The mobilities of all conducting heterostructures $\left(\sim 5 \mathrm{~cm}^{2} / \mathrm{V} \cdot \mathrm{s}\right)$ are consistent with generally reported values of reduced STO having many oxygen vacancies. ${ }^{11}$ The carriers of all heterostructures disappeared after annealing at $600{ }^{\circ} \mathrm{C}$ for 1 hour in an oxygen atmosphere. The carriers disappeared even after annealing at $300{ }^{\circ} \mathrm{C}$ for 1 hour in an oxygen atmosphere. These 
facts provide additional evidence that the source of the carriers was generated by oxygen vacancies on the STO side.

The transfer of the oxygen between LAO and STO has been experimentally reported during the growth of each oxide grown by PLD using an ${ }^{18} \mathrm{O}$ isotope by means of dynamic secondary ion mass spectroscopy (D-SIMS). ${ }^{17}$ Oxygen transfer was observed at high growth temperature $\left(750{ }^{\circ} \mathrm{C}\right)$ as the thick LAO film $(>50 \mathrm{~nm})$ was grown on the STO substrate. However, the oxygen transfer was significantly reduced as the growth temperature decreased below $650^{\circ} \mathrm{C}$.

When it comes to the ALD process, oxygen transfer and reduction of the substrate is also possible provided the thermodynamic condition is satisfied and the reaction kinetics are fast enough. The metal precursor molecules are introduced on the substrate separately without overlapping the oxygen source in the ALD process. Usually, these metal precursor molecules tend to be oxidized by scavenging the nearby oxygen. ${ }^{32}$ The substrate material was reduced during the pulse of the metal precursor without introducing an oxygen source, such as an $\mathrm{H}_{2} \mathrm{O}$ or $\mathrm{O}_{3}$ vapor, by means of oxidation of the metal precursor. ${ }^{32}$ However, the kinetics of the redox reaction can be limited by the low growth temperature of ALD and the strong bond of complex ligands attached to the metal precursor molecules in the ALD reaction. 
The Gibbs free energy of reaction $\left(\Delta G_{r}\right)$ can indicate whether the reduction of the STO

substrate by TMA during the $\mathrm{Al}_{2} \mathrm{O}_{3}$ ALD process is feasible. ${ }^{33-35}$ Possible overall reactions for the reduction of the STO substrate by the TMA at $573 \mathrm{~K}$ are the following:

$$
\begin{aligned}
2 \mathrm{Al}\left(\mathrm{CH}_{3}\right)_{3}+8 \mathrm{TiO}_{2} \Rightarrow>\mathrm{Al}_{2} \mathrm{O}_{3}+4 \mathrm{Ti}_{2} \mathrm{O}_{3}+3 \mathrm{CH}_{4}(\mathrm{~g})+\frac{3}{2} \mathrm{C}_{2} \mathrm{H}_{4}(\mathrm{~g})+\frac{1}{2} \mathrm{O}_{2}(\mathrm{~g}) & \\
\Delta G_{r, 573 \mathrm{~K}} & =-947.156 \mathrm{~kJ} / \mathrm{mol}
\end{aligned}
$$

or

$$
\begin{array}{r}
2 \mathrm{Al}\left(\mathrm{CH}_{3}\right)_{3}+10 \mathrm{TiO}_{2} \Rightarrow \mathrm{Al}_{2} \mathrm{O}_{3}+5 \mathrm{Ti}_{2} \mathrm{O}_{3}+3 \mathrm{CH}_{4}(\mathrm{~g})+\mathrm{C}_{2} \mathrm{H}_{4}(\mathrm{~g})+\mathrm{CO}_{2}(\mathrm{~g})+\mathrm{H}_{2}(\mathrm{~g}) \\
\Delta G_{r, 573 \mathrm{~K}}=-1062.726 \mathrm{~kJ} / \mathrm{mol}
\end{array}
$$

The reaction pathways were expected based on the reports that $\mathrm{CH}_{4}$ gas was mainly produced with small amounts of $\mathrm{C}_{2} \mathrm{H}_{4}$ and $\mathrm{CO}_{2}$ gases as byproducts when TMA dissociates in the presence of oxygen during the $\mathrm{Al}_{2} \mathrm{O}_{3}$ ALD process. ${ }^{36,37}$ The change in Gibbs free energies $\left(\Delta G_{r}\right)$ is negative for reaction pathways (1) and (2) because of the formation of strong Al-O bonds. Thus, at equilibrium, the oxidation of TMA molecules can drive a thermodynamically favorable reduction of STO substrates. ${ }^{38,39}$ Of course, other gaseous byproducts, such as $\mathrm{CO}$ or $\mathrm{H}_{2} \mathrm{CO}$, are also possible, but large negative free energy changes also favor these reactions going to completion at equilibrium. 
In one experiment, reduction of the STO by the injection of TMA alone did not occur,

which means that the thermal energy was not enough to overcome the activation energy due to the slow kinetics at a reaction temperature of $300{ }^{\circ} \mathrm{C}$, even though the thermodynamic condition was satisfied. However, reduction of the STO did happen when LAO, YAO and $\mathrm{Al}_{2} \mathrm{O}_{3}$ films were thicker than their critical thicknesses. As a result, the repetitive pulse (55 cycles) of the Al precursor, TMA, which was used for the deposition of the $\mathrm{LAO}, \mathrm{YAO}$ and $\mathrm{Al}_{2} \mathrm{O}_{3}$ films, on the STO substrate without introducing an oxygen source $\left(\mathrm{H}_{2} \mathrm{O}\right)$ did not induce the reduction of the STO substrate at $300^{\circ} \mathrm{C}$ because of the absence of the $\mathrm{LAO}, \mathrm{YAO}$ and $\mathrm{Al}_{2} \mathrm{O}_{3}$ layers. This is also the case when the repetitive pulses $\left(55\right.$ cycles) of TMA are applied to the $\mathrm{Y}_{2} \mathrm{O}_{3}$ layers previously grown on the STO substrate, irrespective of the $\mathrm{Y}_{2} \mathrm{O}_{3}$ film thickness (Fig. S6 (a)). It should be noted that the interface of the $\mathrm{Y}_{2} \mathrm{O}_{3} / \mathrm{STO}$ heterostructure is insulating as shown in Fig. 3 (b). In this case, the carriers were generated by means of following the deposition of a $6 \mathrm{~nm}$ thick LAO layer on top of the $\mathrm{Y}_{2} \mathrm{O}_{3} / \mathrm{STO}$ heterostructure as shown in Fig. S6 (a). There still exists a required critical thickness of $\mathrm{LAO}$ and $\mathrm{Al}_{2} \mathrm{O}_{3}$ layers when those layers are grown on top of the $\mathrm{Y}_{2} \mathrm{O}_{3}$ layer (4.7 nm-thick) to create carriers, which emphasizes the important role of pregrown LAO and $\mathrm{Al}_{2} \mathrm{O}_{3}$ layers (Fig. $\mathrm{S} 6$ (b)). $\mathrm{LAO}$ and $\mathrm{Al}_{2} \mathrm{O}_{3}$ layers that are thicker than the critical thickness are necessary for the redox reaction even on the $\mathrm{Y}_{2} \mathrm{O}_{3} / \mathrm{STO}$ heterostructure; thus the reduction of the STO can occur during the metal precursor pulse. As discussed above, 
the carriers were generated only after growing a certain-thickness LAO (>3 nm), YAO (>4 nm) and $\mathrm{Al}_{2} \mathrm{O}_{3}(>1.2 \mathrm{~nm})$ layers on the STO substrate at $300{ }^{\circ} \mathrm{C}$. An important feature is that the $\mathrm{Al}_{2} \mathrm{O}_{3}$ component is always included in those oxides, such as LAO, YAO and $\mathrm{Al}_{2} \mathrm{O}_{3}$, which generated the carriers in an interaction with the STO. Here, we claim that $\mathrm{Al}_{2} \mathrm{O}_{3}(>1.2 \mathrm{~nm})$ acts as a catalyst for the reaction; thus the redox reaction of the STO substrate can occur when the TMA molecules are introduced. The $\mathrm{Al}_{2} \mathrm{O}_{3}$ layer $(>1.2 \mathrm{~nm})$ promoted the kinetics of the redox reaction. Therefore, the redox reaction is strongly enhanced at the interface, which results in the oxygen vacancies generated on the STO surface by means of the TMA molecules' oxidation at $300{ }^{\circ} \mathrm{C}$. The minimum required $\mathrm{Al}_{2} \mathrm{O}_{3}$ amount for the carrier generation was estimated by $\sim 15$ cycles of $\mathrm{Al}_{2} \mathrm{O}_{3} \mathrm{ALD}$, which corresponds to a $1.35 \mathrm{~nm}$-thick $\mathrm{Al}_{2} \mathrm{O}_{3}$ layer. An important fact suggesting that this redox reaction is limited by kinetics is that the carrier density decreased significantly with the decreasing growth temperature (Fig. S7). The carrier density was decreased by a factor of $10^{3}$ at a growth temperature of $250{ }^{\circ} \mathrm{C}$; and it could not be measured at $200{ }^{\circ} \mathrm{C}$ due to the measurement limit (decreased by a factor of $>10^{4}$ ).

It is understood that the outward diffusion of oxygen owing to the redox reaction of the STO is limited by grown oxides such as the LAO, YAO and $\mathrm{Al}_{2} \mathrm{O}_{3}$ layers due to their diffusivity of oxygen. The outward diffusion of oxygen from the interface of the heterostructure would be limited by those oxides; thus, the carrier density does not increase above the critical thickness. 
This is an interesting feature in terms of the self-limiting control of the carrier by blocking the outward diffusion of oxygen in the redox reaction. It has been reported that metallic species such as $\mathrm{Al}, \mathrm{Ti}, \mathrm{Y}, \mathrm{Ba}$ and $\mathrm{Zr}$ can interact with the STO substrate at room temperature, which indicates the interfacial redox reaction occurs, and the interactions happen at the STO surfaces. ${ }^{13,35}$

Based on the above discussion, we expected that the carriers would be generated even though the composition of the YAO layer is varied far from the stoichiometry, as long as the amount of the $\mathrm{Al}_{2} \mathrm{O}_{3}$ component in the YAO layer is enough (> 15 cycles). Figure 4 (d) shows the sheet resistance and carrier density depending on the Y-rich YAO layer thickness. A Y-rich YAO (62.6 at\% of Y) film was grown by an ALD cycle ratio (Y:Al) of 4:1 as determined by RBS (Fig. S1 (c)). Although the composition of the YAO layer is out of the stoichiometric range, the transition behavior was also observed. This result supports that the creation of 2-DEG does not originate from the perovskite nature of the YAO layer. The insulating interface of the YAO/STO heterostructure becomes conducting above the YAO thickness of $\sim 4.5 \mathrm{~nm}$. The critical thickness of $\sim 4.5 \mathrm{~nm}$ is a little bit thicker than the stoichiometric YAO/STO heterostructure $(\sim 4 \mathrm{~nm})$. A Y-rich YAO film $\left(4 \mathrm{Y}_{2} \mathrm{O}_{3}\right.$ cycles per $\mathrm{Al}_{2} \mathrm{O}_{3}$ cycle) is thicker than a stoichiometric YAO film ( $2 \mathrm{Y}_{2} \mathrm{O}_{3}$ cycles per $\mathrm{Al}_{2} \mathrm{O}_{3}$ cycle) because more $\mathrm{Y}_{2} \mathrm{O}_{3}$ ALD cycles are included as the same $\mathrm{Al}_{2} \mathrm{O}_{3}$ cycles in Y-rich YAO ALD than in stoichiometric YAO ALD. The 
minimum required $\mathrm{Al}_{2} \mathrm{O}_{3}$ cycles in the $\mathrm{Y}$-rich $\mathrm{YAO} / \mathrm{STO}$ heterostructure for the carrier generation were almost identical ( 15 cycles of $\left.\mathrm{Al}_{2} \mathrm{O}_{3} \mathrm{ALD}\right)$ with the stoichiometric YAO/STO, and also with the LAO/STO and $\mathrm{Al}_{2} \mathrm{O}_{3} / \mathrm{STO}$ heterostructures, which indicates that the amount of $\mathrm{Al}_{2} \mathrm{O}_{3}$ in the film is the most important factor of the redox reaction. The creation of 2-DEG during the growth of the $\mathrm{Al}_{2} \mathrm{O}_{3}$ layer on the STO surface was schematically described according to the above model in Fig. 6.

Figures 7 (a)-(c) show the variation of sheet resistance, mobility and sheet carrier density acquired from Hall measurement results depending on the measurement temperature of the several heterostructures. The sheet resistance variations of all heterostructures were decreased with a decreasing temperature because the mobility increases with a decreasing temperature (Fig. 7 (a)). The mobility variations were identical for all heterostructures which indicates the mobilities were governed by the STO, and the increasing mobility with decreasing temperature is a typical property of STO (Fig. 7 (b)). ${ }^{28,40}$ The mobility was further increased with decreasing temperature down to $30 \mathrm{~K}$ (Fig. S8). The sheet carrier density of the LAO/STO heterostructure was slowly decreased with decreasing temperature, and the sheet carrier density of the $\mathrm{Al}_{2} \mathrm{O}_{3} / \mathrm{STO}$ heterostructure was decreased slightly faster than the LAO-based heterostructure (Fig. 7 (c)). However, the insertion of the $\mathrm{Y}_{2} \mathrm{O}_{3}$ layer between the STO substrates and the $\mathrm{LAO}$ or $\mathrm{Al}_{2} \mathrm{O}_{3}$ films produced more metallic channel $\left(\mathrm{E}_{\mathrm{a}}<10 \mathrm{meV}\right)$ where 
the carrier density was not decreased with decreasing temperature. Figure 7 (d) shows the Arrhenius plot of the sheet carrier densities versus temperature, which gives the activation energy from the slope. The activation energies were close to zero in the $\mathrm{LAO} / \mathrm{Y}_{2} \mathrm{O}_{3} / \mathrm{STO}$ and $\mathrm{Al}_{2} \mathrm{O}_{3} / \mathrm{Y}_{2} \mathrm{O}_{3} / \mathrm{STO}$ heterostructures, which indicates metallic channels were formed. At room temperature, the sheet resistance was even decreased from $1.1 \times 10^{5}$ to $6.72 \times 10^{4} \Omega /$ sq. when the $\mathrm{Y}_{2} \mathrm{O}_{3}$ layer was inserted between the LAO layer and the STO substrate. The sheet carrier density was increased from $1.16 \times 10^{13}$ to $1.87 \times 10^{13} / \mathrm{cm}^{2}$. The role of $\mathrm{Y}_{2} \mathrm{O}_{3}$ between LAO and STO is totally different from that of the epitaxially grown $\mathrm{STO} / \mathrm{Y}_{2} \mathrm{O}_{3} / \mathrm{STO}$ heterostructure, where the single atomic layer of $\mathrm{Y}_{2} \mathrm{O}_{3}$ induced an insulating interface, ${ }^{41}$ because the electronic reconstruction theory does not fit our system. Although the carrier densities decrease slightly with decreasing temperature in the $\mathrm{LAO} / \mathrm{STO}$ and $\mathrm{Al}_{2} \mathrm{O}_{3} / \mathrm{STO}$ heterostructures, the activation energies were very small $\left(\mathrm{E}_{\mathrm{a}}<30 \mathrm{meV}\right)$ and consistent with the oxygen-deficient $\mathrm{STO}^{42}$ as shown in Fig. 7 (d) which indicates that conducting channels were successfully formed.

\section{Conclusions}

Up to now, a physical vapor deposition method, such as PLD, was used to generate 2DEG to grow an epitaxial LAO film on an STO substrate. Here, we showed that 2-DEG can be created by growing an amorphous LAO layer as well as $\mathrm{YAO}$ and $\mathrm{Al}_{2} \mathrm{O}_{3}$ layers grown by the 
ALD process on an STO substrate. It was revealed that the key factor for the creation of 2-DEG was an $\mathrm{Al}_{2} \mathrm{O}_{3}$ ALD process forming oxygen vacancies in the STO by oxidation of the TMA. In practice, the ALD technique has been used for the mass production in the semiconductor field. Among them, the ALD of $\mathrm{Al}_{2} \mathrm{O}_{3}$ is strongly recommended in the mass production since it is an easy and cheap process with a large processing window and precise atomic level control. And the TMA precursor has a very simple structure which can induce an ideal ALD reaction. Eventually, the formation of oxygen vacancies on the STO substrate is well-controlled by the ALD process. These heterostructures fabricated at a low temperature $\left(\sim 300^{\circ} \mathrm{C}\right)$ by ALD provide promising opportunities in oxide electronics. In addition, it can allow more chance to the scalability of a device if the 2-DEG can be created by ALD on the epitaxially grown STO films on $\mathrm{SiO}_{2}$; likewise the observation of 2-DEG on the epitaxially grown $\mathrm{STO}$ films on $\mathrm{SiO}_{2}$ according to the recent report by Park. ${ }^{6}$ Thus, the creation and control of 2-DEG by ALD technique using a TMA precursor is of great importance in terms of the realization of device fabrication. Further process optimization and theoretical calculations will aid in the achievement of devices with even higher performance.

II. Methods. Sample Growth. LAO films were deposited on $\mathrm{TiO}_{2}$-terminated (001) STO single crystals purchased from MTI Corporation, and $\mathrm{TiO}_{2}$-termination was achieved by chemical etching. ${ }^{24,25}$ The LAO films were grown at a growth temperature of $300^{\circ} \mathrm{C}$ by ALD in 
a horizontal gas flow reactor at a working pressure of 400 mTorr (base pressure 30 mTorr). All films, including an LAO layer, were grown by $\mathrm{ALD}$ at $300{ }^{\circ} \mathrm{C}$. Lanthanum $\operatorname{tris}\left(N, N^{\prime}-\right.$ diisopropylformamidinate) (Dow Chemical Company) was used as the La-precursor, and $\mathrm{H}_{2} \mathrm{O}$ was used as the oxygen source. TMA (Sigma Aldrich) was used as the Al-precursor and $\mathrm{H}_{2} \mathrm{O}$ was used as the oxygen source for the deposition of $\mathrm{Al}_{2} \mathrm{O}_{3}$. One super cycle consisted of 2 subcycles of $\mathrm{La}_{2} \mathrm{O}_{3}$ and 1 sub-cycle of $\mathrm{Al}_{2} \mathrm{O}_{3}$ for the deposition of the stoichiometric LAO films. A $\mathrm{Y}_{2} \mathrm{O}_{3}$ thin film was deposited by ALD using yttrium tris( $N, N$ '-diisopropylacetamidinate) (Dow Chemical Company) and $\mathrm{H}_{2} \mathrm{O}$ at a growth temperature of $300{ }^{\circ} \mathrm{C}$. A stoichiometric YAO film (51.3 at\% of $\mathrm{Y}$ ) was grown with a super cycle ratio of 2:1 (Y:Al), and Y-rich YAO film (62.6 at\% of $\mathrm{Y}$ ) was grown with a super cycle ratio of 4:1 (Y:Al).

Measurement of Film Properties. The thickness of the film grown on an STO substrate was estimated by X-ray reflectivity (XRR, PANAlytical, X'Pert Pro) measurements using a $\mathrm{Cu} \mathrm{K} \alpha \mathrm{X}$-ray source. The amorphous phase of the film was analyzed by high-resolution TEM (HRTEM, JEOL 2010F) and glancing angle X-ray diffraction (GAXRD). The film surface morphology was investigated by an atomic force microscope (AFM, Asylum, MFP-3D SA). The composition of the film was evaluated by Rutherford back-scattering spectroscopy (RBS) using a $2 \mathrm{MeV} \mathrm{He}^{2+}$ beam. X-ray photoelectron spectroscopy (XPS, PHI, VersaProbe II) measurements were performed in order to determine the valence state of the Ti. For the 
estimation of the $\mathrm{Ti}^{3+}$ depth profile, the angle-resolved XPS measurement was examined with various photoelectron take-off angles. The effective electron escape depth decreases with the decreasing take-off angle; thus the analysis becomes more surface-sensitive.

Electrical Measurement. For the Hall measurement, four 100 nm-thick Au electrodes (diameter of $1 \mathrm{~mm}$ with a $10 \mathrm{~nm}$-thick Ti adhesion layer) were deposited at the corners of $1 \mathrm{~cm}$ square samples by e-beam evaporation (Denton) using a shadow mask after the deposition of the thin films onto the STO substrate. Sheet resistance $\left(\mathrm{R}_{\mathrm{s}}\right)$ and sheet carrier density $\left(\mathrm{n}_{\mathrm{s}}\right)$ were measured by the Hall measurement system using the Van der Pauw configuration, and the mobility was evaluated from the relationship between $R_{s}$ and $n_{s}$. Ohmic contact property was confirmed by I-V measurement between two Au electrodes (Fig. S9). The measuring temperature was controlled by means of vacuum-assisted cooling with the help of liquid nitrogen, which allowed the lowest temperature of $100 \mathrm{~K}$.

\section{AUTHOR INFORMATION}

Corresponding Author*E-mail: gordon@ chemistry.harvard.edu

\section{ACKNOWLEDGMENTS}


The lanthanum and yttrium amidinate precursors were supplied by the Dow Chemical Company. S.W. Lee would like to thank Meng-Ju Sher for assistance with the Hall measurements at low temperatures. This work was performed in part at the Center for Nanoscale Systems (CNS) at Harvard University, a member of the National Nanotechnology Infrastructure Network (NNIN), which is supported by the National Science Foundation under NSF award no. ECS-0335765. 


\section{List of Figures}

Figure 1 (a) cross sectional high-resolution TEM image of LAO/STO showing amorphous LAO layer grown on a single crystalline STO substrate. (b) [001] zone axis electron diffraction pattern at the interfacial region of the LAO/STO heterostructure.

Figure 2 (a) The surface morphology of the $\mathrm{TiO}_{2}$-terminated STO substrate by AFM, which consists of regular terrace structures with a quite smooth flatness (rms roughness of $0.15 \mathrm{~nm}$ ). (b) The height difference between adjacent terraces corresponds to one unit-cell of STO ( $\sim .4$ $\mathrm{nm}$ ). (c) The surface morphology of a $6 \mathrm{~nm}$ thick-LAO film grown on an STO substrate by ALD at $300{ }^{\circ} \mathrm{C}(\mathrm{rms}$ of $0.2 \mathrm{~nm})$. (d) The sheet resistance and sheet carrier density, and (e) mobility as a function of the amorphous LAO film thickness grown on an STO substrate.

Figure 3 (a) The schematic of several heterostructures using various oxide layers. (b) The sheet resistance and carrier density of several heterostructures showing that 2-DEG can be generated by depositing amorphous an $\mathrm{LAO}, \mathrm{YAO}$ and $\mathrm{Al}_{2} \mathrm{O}_{3}$ layer on an STO substrate, but that $\mathrm{La}_{2} \mathrm{O}_{3}$, $\mathrm{Y}_{2} \mathrm{O}_{3}$ and $\mathrm{LaYO}_{3} / \mathrm{STO}$ did not generate any conductivity. 
Figure 4 Sheet resistance and sheet carrier density of (a) $\mathrm{Al}_{2} \mathrm{O}_{3} / \mathrm{STO}$ and (b) LAO/ $\mathrm{Al}_{2} \mathrm{O}_{3} / \mathrm{STO}$ heterostructures as a function of $\mathrm{Al}_{2} \mathrm{O}_{3}$ film thickness. 6 nm-thick LAO films were grown on top of $\mathrm{Al}_{2} \mathrm{O}_{3}$ films in Fig 4 (b). The sheet resistance and sheet carrier density of (c) stoichiometric (51.3 at. \% of $\mathrm{Y}$ ) $\mathrm{YAO} / \mathrm{STO}$ and $\mathrm{Y}$-rich (62.6 at. \% of $\mathrm{Y}$ ) $\mathrm{YAO} / \mathrm{STO}$ heterostructures as a function of YAO film thickness. YAO films were grown by ALD using cycle ratios of 2:1 (Y:Al) and 4:1, respectively.

Figure 5 (a) The normalized Ti $2 \mathrm{p}$ spectra of a 2.5 nm-thick $\mathrm{Al}_{2} \mathrm{O}_{3} / \mathrm{STO}$ heterostructure measured by normal XPS showing more increased $\mathrm{Ti}^{3+}$ signal $(\sim 456.2 \mathrm{eV})$ with $\mathrm{Al}_{2} \mathrm{O}_{3} / \mathrm{STO}$ heterostructure than the bare STO substrate, which indicates the generation of oxygen vacancies in STO during the growth of the $\mathrm{Al}_{2} \mathrm{O}_{3}$ layer by ALD. The signal from the bare STO substrate was used for comparison. (b) Normalized $\mathrm{Ti} 2 \mathrm{p}$ spectra of a $2.5 \mathrm{~nm}$-thick $\mathrm{Al}_{2} \mathrm{O}_{3} / \mathrm{STO}$ heterostructure obtained by angle-resolved XPS showing that the carriers are localized at the interface, where all the spectra were normalized to have the same $\mathrm{Ti}^{4+}$ peak height.

Figure 6 Schematic diagram of 2-DEG creation by reduction of STO by TMA during the growth of an $\mathrm{Al}_{2} \mathrm{O}_{3}$ film at $300{ }^{\circ} \mathrm{C}$. The $\mathrm{Al}_{2} \mathrm{O}_{3}$ layer (>15 cycles of $\mathrm{Al}_{2} \mathrm{O}_{3} \mathrm{ALD}$ ) promoted the kinetics 
of the redox reaction; thus the oxygen vacancies could be generated on the STO surface by oxidation of TMA molecules.

Figure 7 (a)-(c) The variation of sheet resistance, mobility and sheet carrier density from Hall measurements depending on the measurement temperature of the several heterostructures. (d) The activation energies of the several heterostructures by arrhenius plotting of the temperaturedependence of the sheet carrier densities, which indicate metallic channels were successfully formed $\left(\mathrm{E}_{\mathrm{a}}<30 \mathrm{meV}\right)$.

Figure S1 The composition of (a) LAO film (17 nm-thick) and YAO (18 nm) films with cycle ratios (Y:Al) of (b) 2:1 and (c) 4:1, evaluated by Rutherford back-scattering spectroscopy (RBS) using a $2 \mathrm{MeV} \mathrm{He}^{2+}$ beam. The estimated atomic ratio of $\mathrm{La} /[\mathrm{La}+\mathrm{Al}]$ in the $\mathrm{LAO}$ film was $51.4 \%$, which indicates the grown film is very close to stoichiometry The estimated atomic ratios of $\mathrm{Y} /[\mathrm{Y}+\mathrm{Al}]$ in $\mathrm{YAO}$ films were 51.3 and $62.6 \%$ with cycle ratios of 2:1 and 4:1, respectively.

Figure $\mathrm{S} 2$ The thickness of (a) LAO, (b) $\mathrm{Al}_{2} \mathrm{O}_{3}$ and (c) YAO films grown on an STO substrate estimated by X-ray reflectivity measurement. Films were grown on $\mathrm{Ru}$ substrates 
simultaneously and the thickness was measured by ellipsometry to confirm the linear growth behavior depends on the deposition cycle number. (d) Representative simulation results of LAO, $\mathrm{Al}_{2} \mathrm{O}_{3}$ and $\mathrm{YAO}$ films grown on the $\mathrm{STO}$ substrate.

Figure $\mathrm{S} 3$ (a) The mobility of $\mathrm{Al}_{2} \mathrm{O}_{3} / \mathrm{STO}$ and $\mathrm{LAO} / \mathrm{Al}_{2} \mathrm{O}_{3} / \mathrm{STO}$ heterostructures depend on the $\mathrm{Al}_{2} \mathrm{O}_{3}$ film thickness. 6 nm-thick LAO films were grown on top of $\mathrm{Al}_{2} \mathrm{O}_{3}$ films to fabricate $\mathrm{LAO} / \mathrm{Al}_{2} \mathrm{O}_{3} / \mathrm{STO}$ heterostructure. (b) The mobility of stoichiometric (51.3\% of Y) YAO/STO and Y-rich (62.6\% of Y) YAO/STO heterostructures as a function of YAO film thickness. YAO films were grown by ALD using cycle ratios of 2:1 (Y:Al) and 4:1, respectively.

Figure S4 Glancing angle X-ray diffraction spectra of LAO/STO, $\mathrm{Al}_{2} \mathrm{O}_{3} / \mathrm{STO}$ and $\mathrm{YAO}(51.3 \%$ of Y)/STO heterostructures showing that amorphous films were grown on the STO substrates.

Figure S5 The illustration of the angle-resolved XPS analysis with a $2.5 \mathrm{~nm}$-thick $\mathrm{Al}_{2} \mathrm{O}_{3} / \mathrm{STO}$ heterostructure. The analysis sampling depth changes as a function of the photoelectron take-off angle. The photoelectron take-off angle $(\Theta)$ is defined as the angle between the sample surface and detector. 
Figure S6 (a) Repetitive pulses of TMA (55 cycles) on $\mathrm{Y}_{2} \mathrm{O}_{3} / \mathrm{STO}$ heterostructure depend on the $\mathrm{Y}_{2} \mathrm{O}_{3}$ film thickness without introducing an oxygen source $\left(\mathrm{H}_{2} \mathrm{O}\right)$, which did not generate the carriers. However, the carriers were generated by means of following the deposition of a $6 \mathrm{~nm}$ thick LAO layer on top of the $\mathrm{Y}_{2} \mathrm{O}_{3} / \mathrm{STO}$ heterostructure. (b) A required critical thickness of LAO and $\mathrm{Al}_{2} \mathrm{O}_{3}$ layers grown on top of the $\mathrm{Y}_{2} \mathrm{O}_{3}$ layer (4.7 nm-thick) to create 2-DEG, which underlines the important role of $\mathrm{LAO}$ and $\mathrm{Al}_{2} \mathrm{O}_{3}$ layers.

Figure S7 The influence of ALD growth temperature on the conductivity of LAO/STO heterostructure. The density of carriers decreased drastically with decreasing growth temperature.

Figure S8 The mobility of LAO/STO heterostructure at the low temperature (down to $30 \mathrm{~K}$ ).

Figure S9 Ohmic I-V behavior between two Au electrodes using KEITHLEY 2400 sourcemeter. 
References

(1) Mannhart, J.; Schlom, D. G. Science 2010, 327, 1607-1611.

(2) Ohtomo, A.; Hwang, H. Y. Nature 2004, 427, 423-426.

(3) Thiel, S.; Hammerl, G.; Schmehl, A.; Schneider, C. W.; Mannhart, J. Science 2006, 313, 1942-1945.

(4) Xie, Y.; Bell, C.; Yajima, T.; Hikita, Y.; Hwang, H. Y. Nano Letters 2010, 10, 2588-2591.

(5) Rijnders, G.; Blank, D. H. A. Nat Mater 2008, 7, 270-271.

(6) Park, J. W.; Bogorin, D. F.; Cen, C.; Felker, D. A.; Zhang, Y.;

Nelson, C. T.; Bark, C. W.; Folkman, C. M.; Pan, X. Q.; Rzchowski, M. S.; Levy, J.; Eom, C. B. Nat Commun 2010, 1, 94.

(7) Cen, C.; Thiel, S.; Hammerl, G.; Schneider, C. W.; Andersen, K. E.; Hellberg, C. S.; Mannhart, J.; Levy, J. Nat Mater 2008, 7, 298-302.

(8) Segal, Y.; Ngai, J. H.; Reiner, J. W.; Walker, F. J.; Ahn, C. H. Physical Review B 2009, 80, 241107.

(9) Nakagawa, N.; Hwang, H. Y.; Muller, D. A. Nat Mater 2006, 5, 204-209.

(10) Chambers, S. A. Adv. Mater. 2010, 22, 219-248.

(11) Herranz, G.; Basletić, M.; Bibes, M.; Carrétéro, C.; Tafra, E.; Jacquet, E.; Bouzehouane, K.; Deranlot, C.; Hamzić, A.; Broto, J. M.; Barthélémy, A.; Fert, A. Physical Review Letters 2007, 98, 216803.

(12) Siemons, W.; Koster, G.; Yamamoto, H.; Harrison, W. A.; Lucovsky, G.; Geballe, T. H.; Blank, D. H. A.; Beasley, M. R. Physical Review Letters 2007, 98, 196802.

(13) Chen, Y.; Pryds, N.; Kleibeuker, J. e. E.; Koster, G.; Sun, J.; Stamate, E.; Shen, B.; Rijnders, G.; Linderoth, S. Nano Letters 2011, 11, 3774-3778.

(14) Kalabukhov, A.; Gunnarsson, R.; Börjesson, J.; Olsson, E.; Claeson, T.; Winkler, D. Physical Review B 2007, 75, 121404.

(15) Zhang, L.; Zhou, X.-F.; Wang, H.-T.; Xu, J.-J.; Li, J.; Wang, E. G.; Wei, S.-H. Physical Review B 2010, 82, 125412.

(16) Zhong, Z.; Xu, P. X.; Kelly, P. J. Physical Review B 2010, 82, 165127. 
(17) Schneider, C. W. E., M.; Marozau, I.; Conder, K.; Doebeli, M.; Hu, Yi; Mallepell, M.; Wokaun, A.; Lippert, T. Appl. Phys. Lett. 2010, 97, 192107.

(18) Huijben, M.; Rijnders, G.; Blank, D. H. A.; Bals, S.; Aert, S. V.; Verbeeck, J.; Tendeloo, G. V.; Brinkman, A.; Hilgenkamp, H. Nat Mater 2006, 5, 556-560.

(19) Qiao, L.; Droubay, T. C.; Varga, T.; Bowden, M. E.; Shutthanandan, V.; Zhu, Z.; Kaspar, T. C.; Chambers, S. A. Physical Review B 2011, 83, 085408.

(20) Liao, Y. C.; Kopp, T.; Richter, C.; Rosch, A.; Mannhart, J. Physical Review B 2011, 83, 075402.

(21) Leskelä, M.; Ritala, M. Angewandte Chemie International Edition 2003, 42, 5548-5554.

(22) Puurunen, R. L. J. Appl. Phys. 2005, 97, 121301.

(23) Jiang, J. C.; Pan, X. Q.; Chen, C. L. Applied Physics Letters 1998, 72, 909-911.

(24) Kawasaki, M.; Takahashi, K.; Maeda, T.; Tsuchiya, R.; Shinohara, M.; Ishiyama, O.; Yonezawa, T.; Yoshimoto, M.; Koinuma, H. Science 1994, 266, 1540-1542.

(25) Koster, G.; Kropman, B. L.; Rijnders, G. J. H. M.; Blank, D. H. A.; Rogalla, H. Applied Physics Letters 1998, 73, 2920-2922.

(26) Diehl, R.; Brandt, G. Materials Research Bulletin 1975, 10, 85-90.

(27) Frederikse, H. P. R.; Hosler, W. R. Physical Review 1967, 161, 822-827.

(28) Tufte, O. N.; Chapman, P. W. Physical Review 1967, 155, 796-802.

(29) Kim, S. K.; Lee, S. W.; Han, J. H.; Lee, B.; Han, S.; Hwang, C. S. Advanced Functional Materials 2010, 20, 2989-3003.

(30) Liang, X.; Meng, Z.; Wu, W. Journal of the American Ceramic Society 2004, 87, 2218-2222.

(31) Chen, T. L., X. M.; Wu, W. B. J. Appl. Phys. 2005, 98, 064109.

(32) Lee, S. W.; Han, J. H.; Kim, S. K.; Han, S.; Lee, W.; Hwang, C. S. Chemistry of Materials 2011, 23, 976-983.

(33) Charles T, C. Surface Science Reports 1997, 27, 1-111.

(34) Ulrike, D. Surface Science Reports 2003, 48, 53-229.

(35) Fu, Q.; Wagner, T. Surface Science Reports 2007, 62, 431-498. 
(36) Goldstein, D. N.; McCormick, J. A.; George, S. M. The Journal of Physical Chemistry C 2008, 112, 19530-19539.

(37) Elliott, S. D.; Scarel, G.; Wiemer, C.; Fanciulli, M.; Pavia, G. Chemistry of Materials 2006, 18, 3764-3773.

(38) HSC Chemistry, 5.11 edition; Outokumpu Research Oy: Pori, Finland.

(39) George, S. M. Chemical Reviews 2009, 110, 111-131.

(40) Son, J.; Moetakef, P.; Jalan, B.; Bierwagen, O.; Wright, N. J.; Engel-Herbert, R.; Stemmer, S. Nat Mater 2010, 9, 482-484.

(41) Jang, H. W.; Felker, D. A.; Bark, C. W.; Wang, Y.; Niranjan, M. K.; Nelson, C. T.; Zhang, Y.; Su, D.; Folkman, C. M.; Baek, S. H.; Lee, S.; Janicka, K.; Zhu, Y.; Pan, X. Q.; Fong, D. D.; Tsymbal, E. Y.; Rzchowski, M. S.; Eom, C. B. Science 2011, 331, 886-889.

(42) Liu, Z. Q.; Leusink, D. P.; Wang, X.; Lü, W. M.; Gopinadhan, K.; Annadi, A.; Zhao, Y. L.; Huang, X. H.; Zeng, S. W.; Huang, Z.; Srivastava, A.; Dhar, S.; Venkatesan, T.; Ariando Physical Review Letters 2011, 107, 146802. 


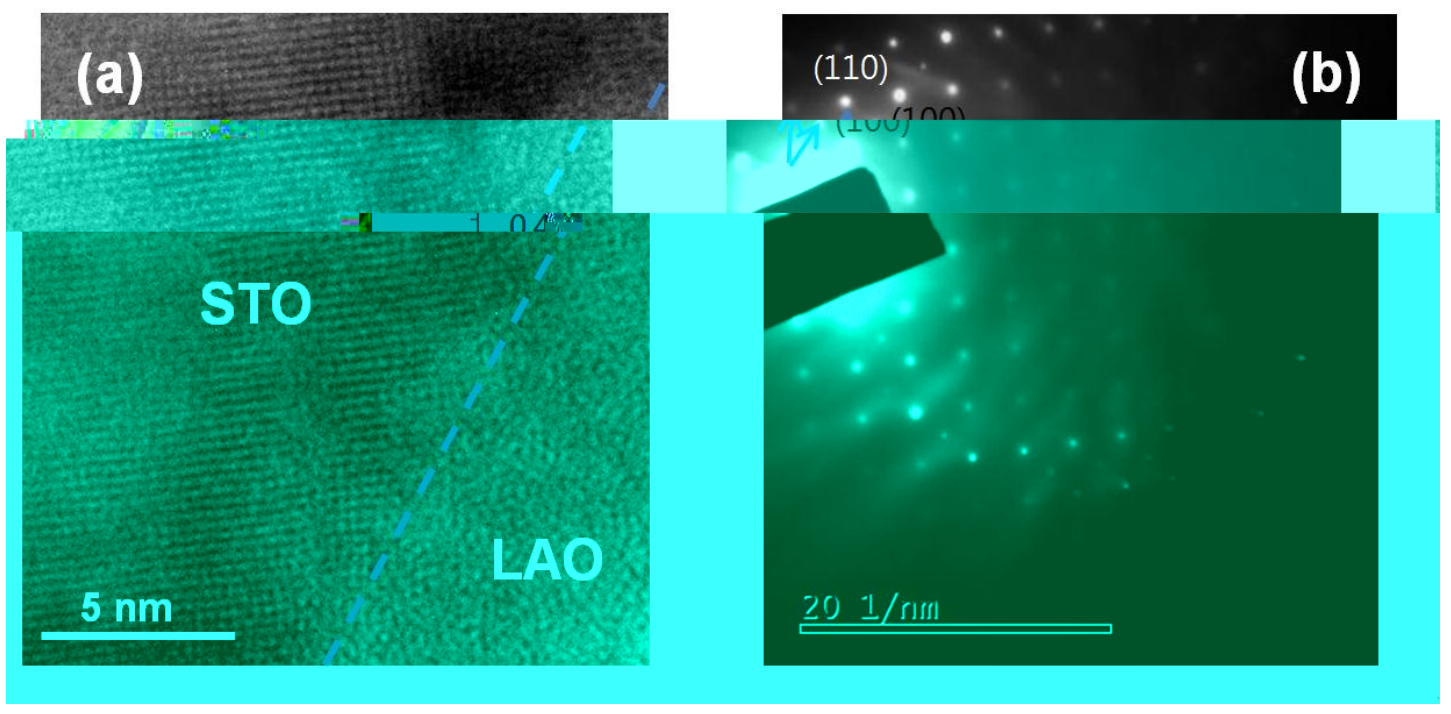

Figure 1 (a) cross sectional high-resolution TEM image of LAO/STO showing amorphous LAO layer grown on a single crystalline STO substrate. (b) [001] zone axis electron diffraction pattern at the interfacial region of the LAO/STO heterostructure. 

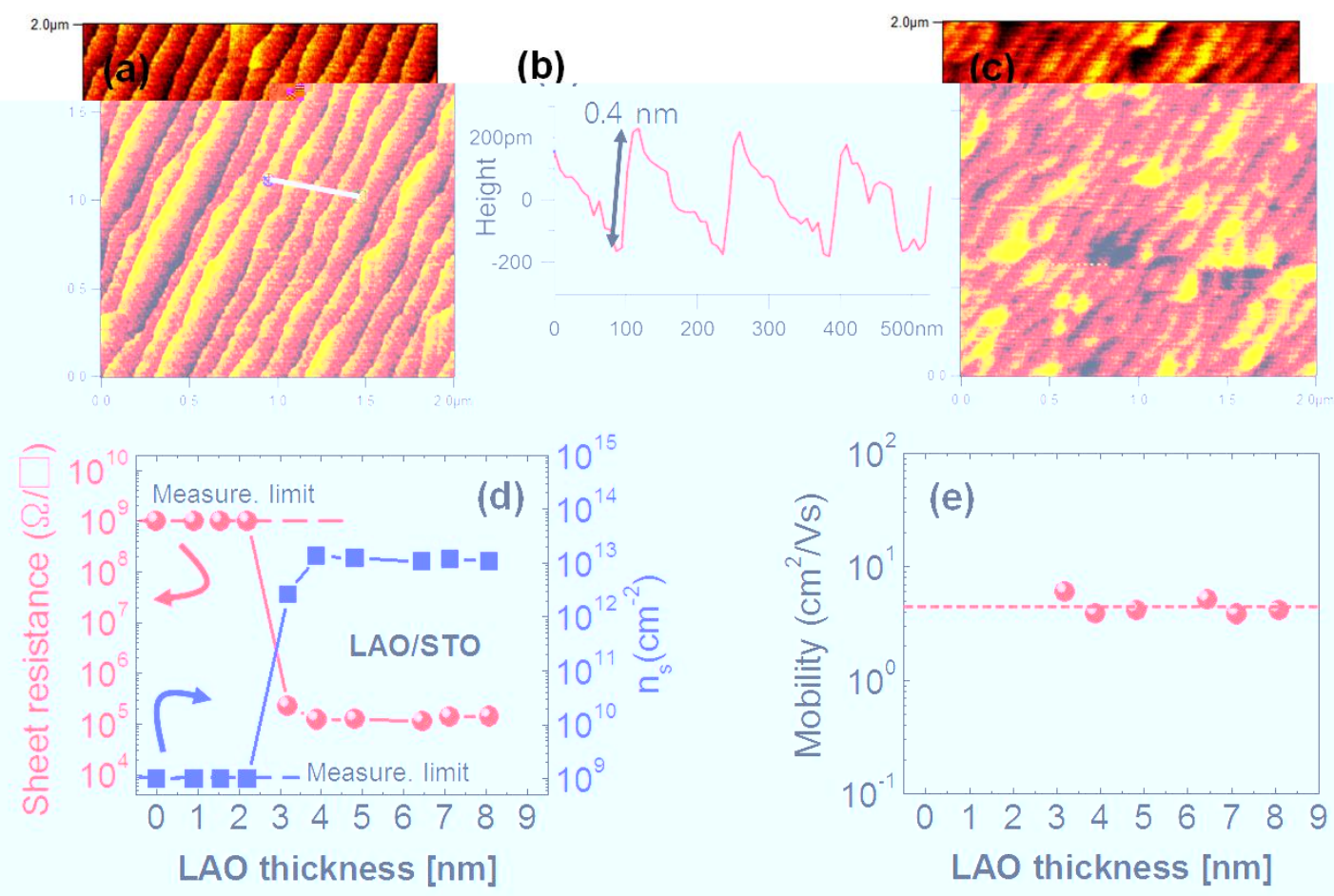

Figure 2 (a) The surface morphology of the $\mathrm{TiO}_{2}$-terminated STO substrate by AFM, which consists of regular terrace structures with a quite smooth flatness (rms roughness of $0.15 \mathrm{~nm}$ ). (b) The height difference between adjacent terraces corresponds to one unit-cell of STO ( 0.4 $\mathrm{nm})$. (c) The surface morphology of a $6 \mathrm{~nm}$ thick-LAO film grown on an STO substrate by ALD at $300{ }^{\circ} \mathrm{C}$ (rms of $0.2 \mathrm{~nm}$ ). (d) The sheet resistance and sheet carrier density, and (e) mobility as a function of the amorphous LAO film thickness grown on an STO substrate. 
(a)

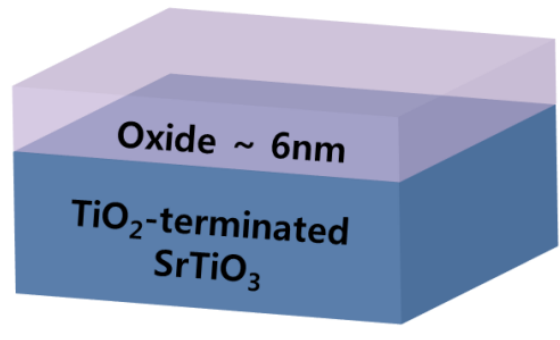

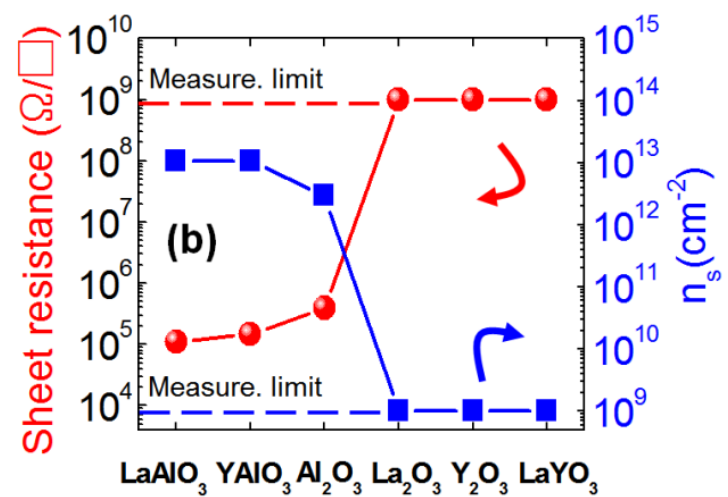

Figure 3 (a) The schematic of several heterostructures using various oxide layers. (b) The sheet resistance and carrier density of several heterostructures showing that 2-DEG can be generated by depositing amorphous an $\mathrm{LAO}, \mathrm{YAO}$ and $\mathrm{Al}_{2} \mathrm{O}_{3}$ layer on an STO substrate, but that $\mathrm{La}_{2} \mathrm{O}_{3}$, $\mathrm{Y}_{2} \mathrm{O}_{3}$ and $\mathrm{LaYO}_{3} / \mathrm{STO}$ did not generate any conductivity. 

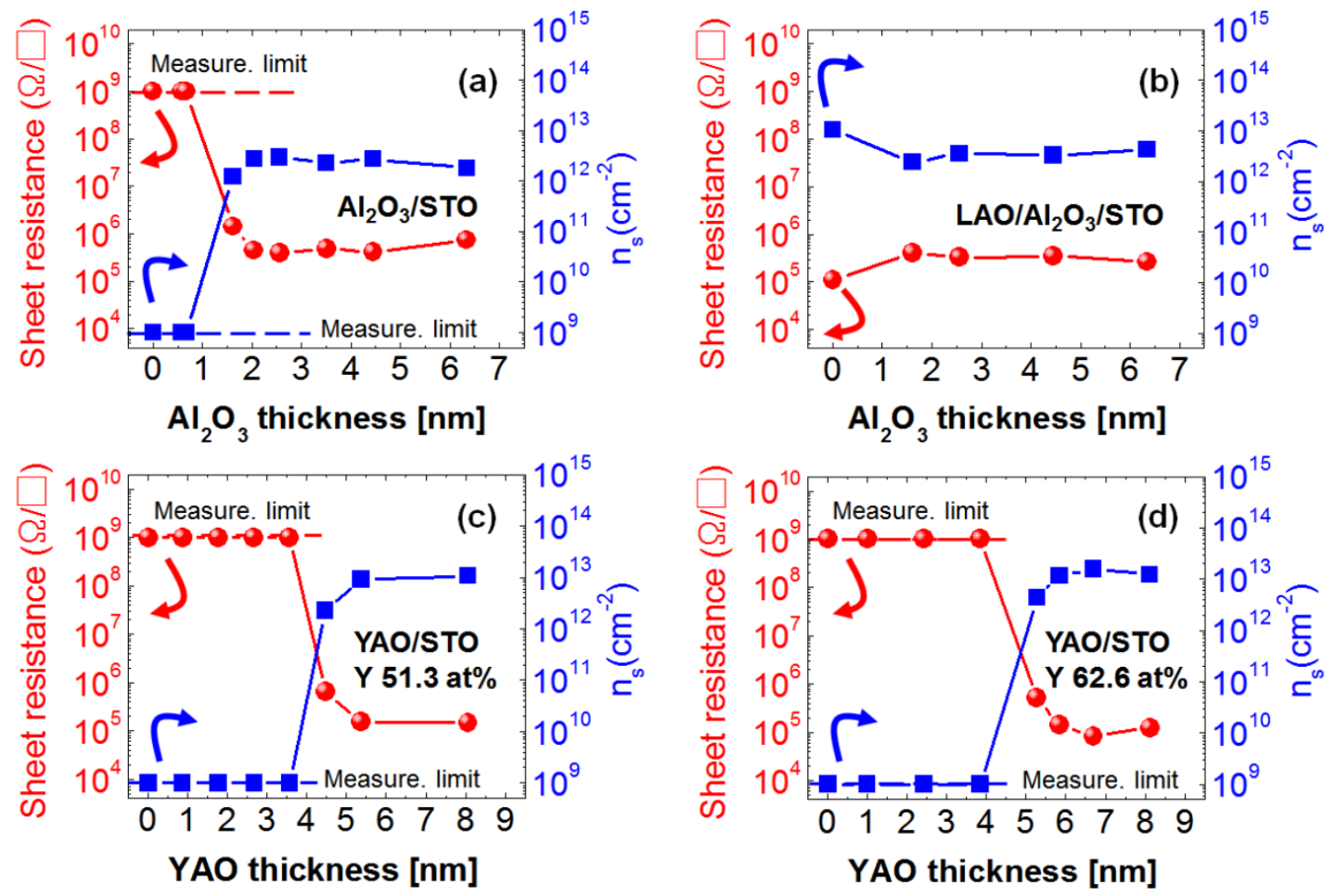

Figure 4 The sheet resistance and sheet carrier density of (a) $\mathrm{Al}_{2} \mathrm{O}_{3} / \mathrm{STO}$ and (b) LAO/ $\mathrm{Al}_{2} \mathrm{O}_{3} / \mathrm{STO}$ heterostructures as a function of $\mathrm{Al}_{2} \mathrm{O}_{3}$ film thickness. 6 nm-thick LAO films were grown on top of $\mathrm{Al}_{2} \mathrm{O}_{3}$ films in Fig 4 (b). The sheet resistance and sheet carrier density of (c) stoichiometric (51.3 at. $\%$ of $\mathrm{Y}$ ) YAO/STO and Y-rich (62.6 at. $\%$ of Y) YAO/STO heterostructures as a function of YAO film thickness. YAO films were grown by ALD using cycle ratios of 2:1 (Y:Al) and 4:1, respectively. 

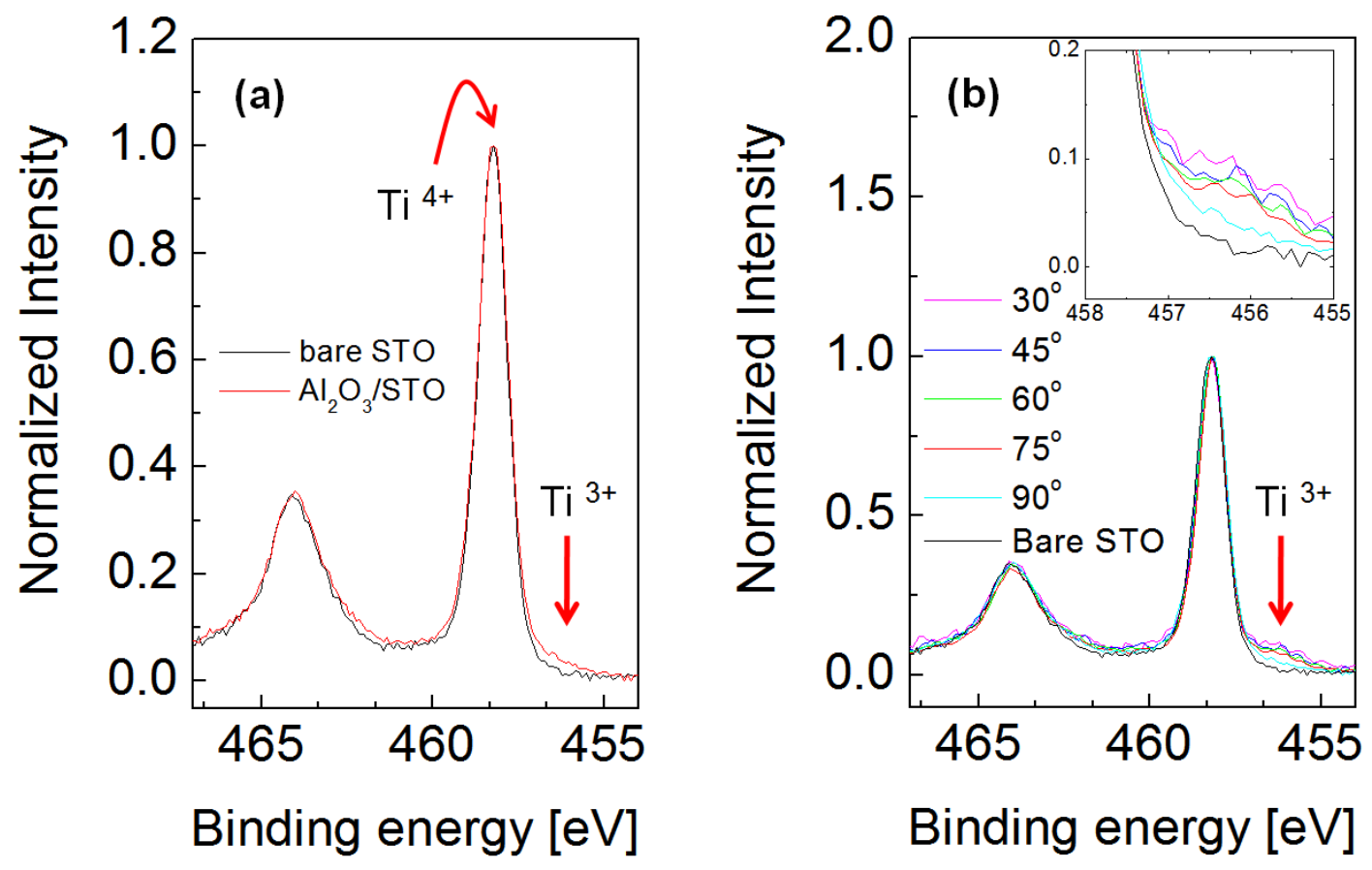

Figure 5 (a) The normalized $\mathrm{Ti} 2 \mathrm{p}$ spectra of a 2.5 nm-thick $\mathrm{Al}_{2} \mathrm{O}_{3} / \mathrm{STO}$ heterostructure measured by normal XPS showing more increased $\mathrm{Ti}^{3+}$ signal $(\sim 456.2 \mathrm{eV})$ with $\mathrm{Al}_{2} \mathrm{O}_{3} / \mathrm{STO}$ heterostructure than the bare STO substrate, which indicates the generation of oxygen vacancies in STO during the growth of the $\mathrm{Al}_{2} \mathrm{O}_{3}$ layer by ALD. The signal from the bare STO substrate was used for comparison. (b) Normalized $\mathrm{Ti} 2 \mathrm{p}$ spectra of a $2.5 \mathrm{~nm}$-thick $\mathrm{Al}_{2} \mathrm{O}_{3} / \mathrm{STO}$ heterostructure obtained by angle-resolved XPS showing that the carriers are localized at the interface, where all the spectra were normalized to have the same $\mathrm{Ti}^{4+}$ peak height. 


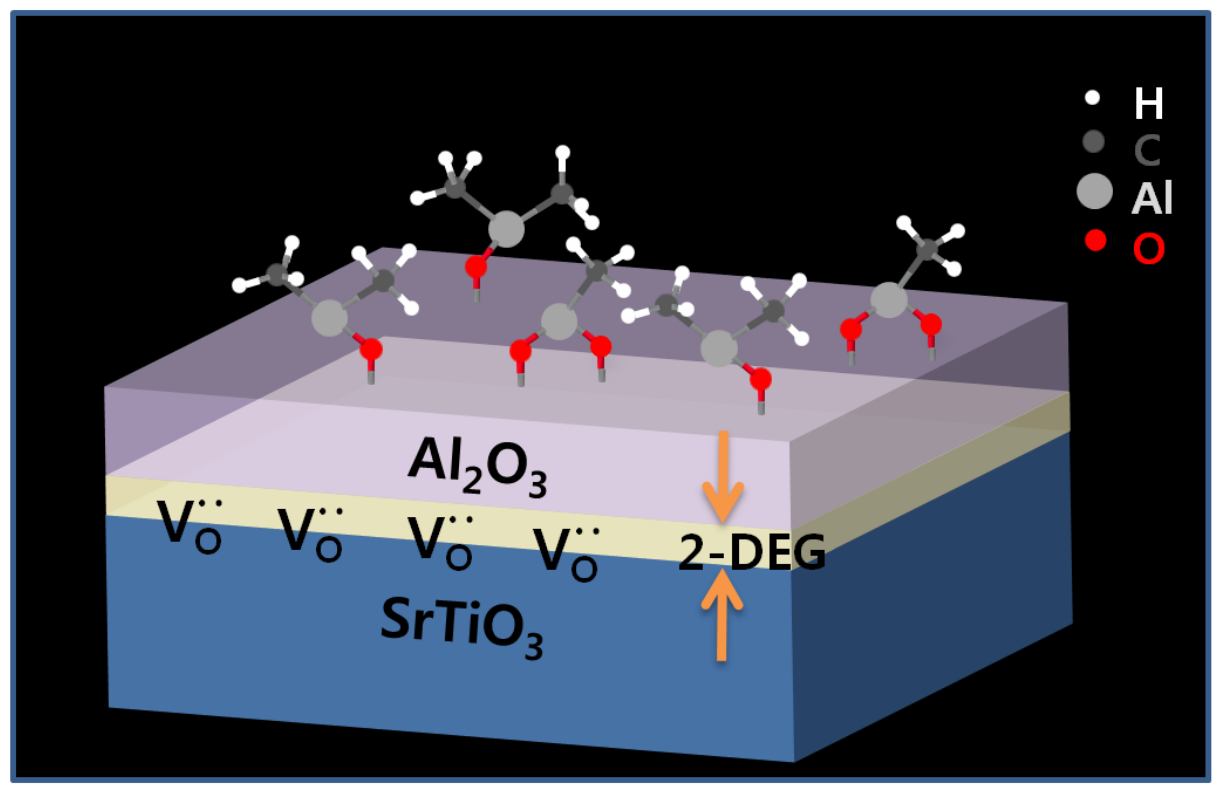

Figure 6 Schematic diagram of 2-DEG creation by reduction of STO by TMA during the growth of $\mathrm{Al}_{2} \mathrm{O}_{3}$ film at $300{ }^{\circ} \mathrm{C}$. The $\mathrm{Al}_{2} \mathrm{O}_{3}$ layer ( $>15$ cycles of $\mathrm{Al}_{2} \mathrm{O}_{3} \mathrm{ALD}$ ) promoted the kinetics of the redox reaction; thus the oxygen vacancies could be generated on the STO surface by oxidation of TMA molecules. 

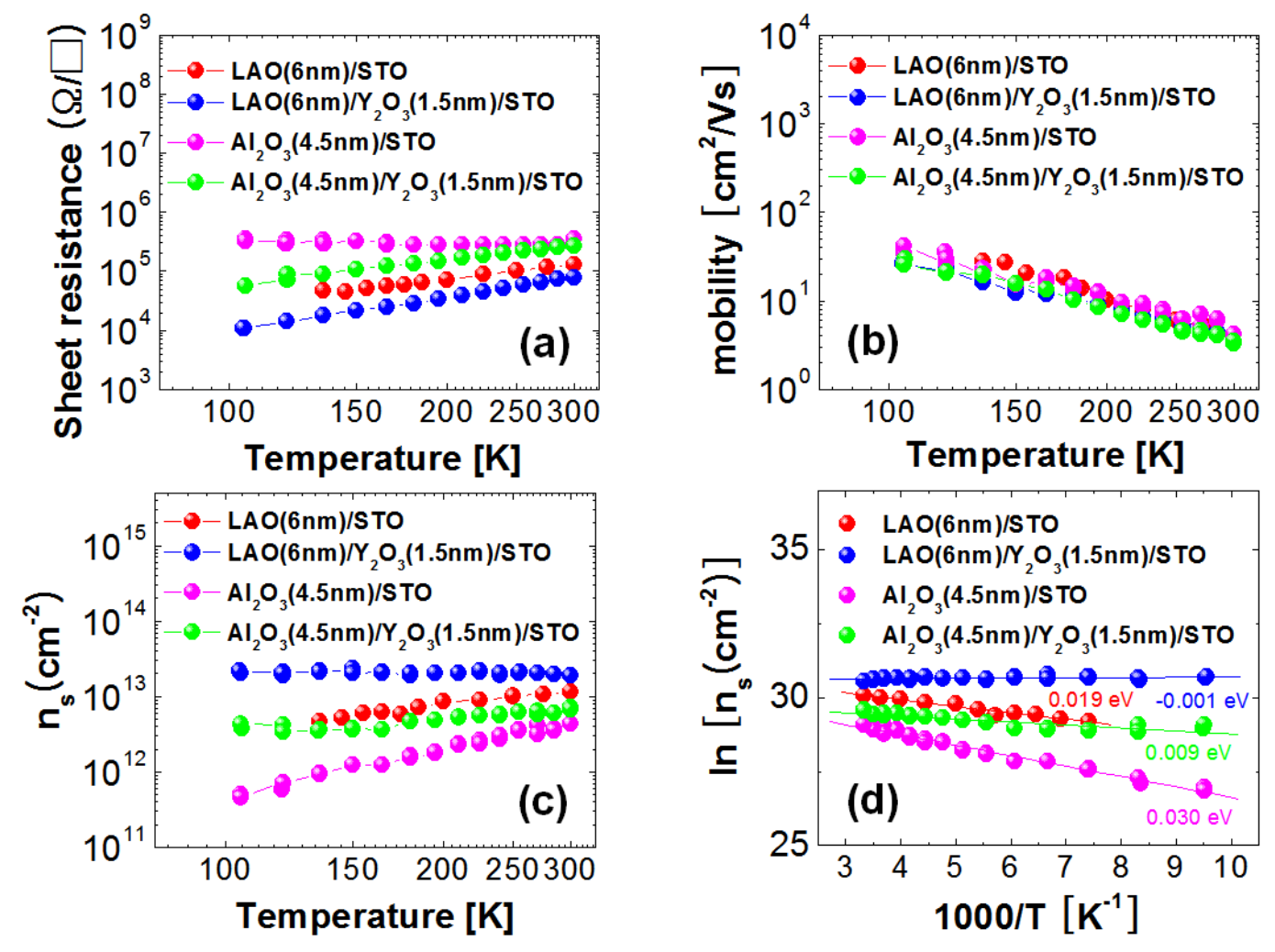

Figure 7 (a)-(c) The variation of sheet resistance, mobility and sheet carrier density from Hall measurements depending on the measurement temperature of the several heterostructures. (d) The activation energies of the several heterostructures by arrhenius plotting of the temperaturedependence of the sheet carrier densities, which indicate metallic channels were successfully formed $\left(\mathrm{E}_{\mathrm{a}}<30 \mathrm{meV}\right)$. 


\title{
Supporting Information for
}

\section{Creation and Control of 2-Dimensional Electron Gas \\ Using Al-based Amorphous Oxides/ $\mathrm{SrTiO}_{3}$ Heterostructures \\ Grown by Atomic Layer Deposition}

\author{
Sang Woon Lee, Yiqun Liu, Jaeyeong Heo, and Roy G. Gordon* \\ Department of Chemistry and Chemical Biology, Harvard University, Cambridge,
}

Massachusetts 02138, USA

\section{Termination of STO}

The STO crystals were ultrasonically soaked in DI water for 20 min prior to the etching in BHF to make Sr-hydroxide complex on the surface of STO which is used to enhance the etch-selectivity of $\mathrm{SrO}$ relative to $\mathrm{TiO}_{2}$ in a buffered $\mathrm{HF}$ solution. And then, the STO crystals were etched in buffered HF solution for $30 \mathrm{~s}$ for the $\mathrm{TiO}_{2}$-surface termination, followed by the annealed at $950{ }^{\circ} \mathrm{C}$ in $\mathrm{O}_{2}$ ambient for $1 \mathrm{hr}$ in the tube furnace for the surface reconstruction. When the substrate was not treated according to the above procedure, the sheet 
resistances of LAO/STO, YAO/STO and $\mathrm{Al}_{2} \mathrm{O}_{3} / \mathrm{STO}$ heterostructures were much higher than those of treated samples by a factor $>1000$.

\section{Thin film growth.}

The LAO films were grown on $\mathrm{TiO}_{2}$-terminated STO substrate at a growth temperature of $300{ }^{\circ} \mathrm{C}$ by atomic layer deposition (ALD) in a horizontal gas flow reactor at a working pressure of 400 mtorr (base pressure 30 mtorr). All films including LAO layer were grown by ALD at $300{ }^{\circ} \mathrm{C}$. Lanthanum tris(N,N'-diisopropylformamidinate) molecules were used as the La-precursor which was kept at $118{ }^{\circ} \mathrm{C}$, and $\mathrm{H}_{2} \mathrm{O}$ was used as the oxygen source which was kept at room temperature. The long enough purge time after each dose was set to be 40 and $80 \mathrm{~s}$, respectively, for the complete removal of excess molecules and preventing of any gas phase reaction. TMA (Sigma Aldrich) was used as the Al-precursor and $\mathrm{H}_{2} \mathrm{O}$ was used as the oxygen source for the deposition of $\mathrm{Al}_{2} \mathrm{O}_{3}$. TMA was kept at room temperature, vaporized into a trap volume $(\sim 3 \mathrm{~mL})$ made of stainless steel and subsequently delivered to the reaction chamber by using pneumatic valves. The purge time after each dose was set to be 40 and $60 \mathrm{~s}$, respectively. One super cycle consists of 2 sub-cycles of $\mathrm{La}_{2} \mathrm{O}_{3}$ and 1 sub-cycle of $\mathrm{Al}_{2} \mathrm{O}_{3}$ for the deposition of stoichiometric LAO films. $\mathrm{Y}_{2} \mathrm{O}_{3}$ thin film was deposited by ALD using yttrium tris-(N,N'diisopropylacetamidinate), $\mathrm{Y}\left(\mathrm{iPr}_{2} \mathrm{amd}\right)_{3}$, and $\mathrm{H}_{2} \mathrm{O}$ at a growth temperature of $300{ }^{\circ} \mathrm{C}$. 
$\mathrm{Y}\left(\mathrm{iPr}_{2} \mathrm{amd}\right)_{3}$ molecules were kept at $130{ }^{\circ} \mathrm{C}$. Stoichiometric $\mathrm{YAO}$ film $(51.3$ at\% of $\mathrm{Y})$ was grown with a super cycle ratio of 2:1 (Y:Al), and Y-rich YAO film (62.6 at\% of Y) was deposited with a super cycle ratio of 4:1 (Y:Al).

\section{Composition of amorphous films (Figures S1)}

The composition of the grown LAO $(17 \mathrm{~nm})$ and YAO $(18 \mathrm{~nm})$ films were evaluated by Rutherford back-scattering spectroscopy (RBS) using $2 \mathrm{MeV} \mathrm{He}^{2+}$ beam as shown in Figs. S1. Glassy carbon (Alfa Aesar) was used as a substrate for RBS analysis, which enables the detection of Al peak separated from the substrate background. The simulation error for atomic density was less than $3 \%$, which gives less than 1.5 at $\%$ variation in calculated $\mathrm{Al}$ concentrations. The carbon substrate was cleaned with $10 \%$ aqueous HF (5 s), deionized water (30 s), and isopropanol (10 s) prior to drying and ultraviolet-ozone cleaning for $3 \mathrm{~min}$ to facilitate the initiation of the film growth. The estimated atomic ratio of $\mathrm{La} /[\mathrm{La}+\mathrm{Al}]$ in $\mathrm{LAO}$ film was $51.4 \%$, which indicates the grown film is very close to the stoichiometry. The estimated atomic ratios of $\mathrm{Y} /[\mathrm{Y}+\mathrm{Al}]$ in $\mathrm{YAO}$ film were 51.3 and 62.6 at\% with cycle ratios (Y:Al) of 2:1 and 4:1, respectively.

\section{Estimation of amorphous film thickness (Figure S2)}


The thickness of the film grown on STO substrate was estimated by X-ray reflectivity measurement. The X-ray reflectivity data were used to evaluate the film thickness, density, and roughness by the least-squares fitting method using the analytical software, X'Pert Reflectivity 1.1. $\mathrm{LAO}, \mathrm{Al}_{2} \mathrm{O}_{3}$ and $\mathrm{YAO}$ films were grown simultaneously on $\mathrm{Ru}$ substrate to confirm the linear growth behavior depending on the deposition cycle number for the thinner regime which was difficult to analyze by XRR due to the weak signal. The estimated thicknesses of (a) LAO, (b) $\mathrm{Al}_{2} \mathrm{O}_{3}$ and (c) YAO films were compared with those measured by ellipsometry, which were grown on Ru substrates simultaneously. The simulation results fit well to the raw data from LAO/STO, $\mathrm{Al}_{2} \mathrm{O}_{3} / \mathrm{STO}$ and YAO/STO heterostructures as shown in Fig. S2 (d). The densities were estimated to $4.85,4.2,4.0 \mathrm{~g} / \mathrm{cm}^{3}$ for $\mathrm{LAO}, \mathrm{YAO}$ and $\mathrm{Al}_{2} \mathrm{O}_{3}$ films, respectively. The growth rates of LAO film obtained from both ellipsometry $(0.328 \mathrm{~nm} /$ super cycle $)$ and XRR $(0.326$ $\mathrm{nm} /$ super cycle) were almost identical which were acquired by the slope of linear fits in Fig. S2 (a). Likewise, the growth rate of $\mathrm{Al}_{2} \mathrm{O}_{3}$ films obtained from ellipsometry $(0.087 \mathrm{~nm} / \mathrm{cycle})$ wase consistent with that from XRR $(0.086 \mathrm{~nm} /$ cycle $)$. The growth behavior of $\mathrm{LAO}$ and $\mathrm{Al}_{2} \mathrm{O}_{3}$ films grown on Ru substrates were quite linear, which suggests that typical linear growth behavior occurs in these ALD processes. The growth rates of YAO films obtained from XRR ( 0.180 and $0.285 \mathrm{~nm} /$ super cycle for the cycle ratios (Y:Al) of 2:1 and 4:1, respectively) were slightly 
lower than those measured by ellipsometry ( 0.191 and $0.318 \mathrm{~nm} /$ super cycle, respectively), which were grown on Ru substrates.

\section{Extraction of the mobility (Figure S3)}

The electron mobility was extracted by Hall measurement using the relation between the conductance, carrier density and mobility. Figure S3 (a) shows the electron mobility of $\mathrm{Al}_{2} \mathrm{O}_{3} / \mathrm{STO}$ and $\mathrm{LAO} / \mathrm{Al}_{2} \mathrm{O}_{3} / \mathrm{STO}$ heterostructures as a function of $\mathrm{Al}_{2} \mathrm{O}_{3}$ film thickness, which shows constant electron mobility irrespective of the $\mathrm{Al}_{2} \mathrm{O}_{3}$ film thickness. Figure $\mathrm{S} 3$ (b) shows the electron mobility of YAO/STO heterostructures as a function of YAO film thickness. The electron mobility was constant regardless of the Y composition and thickness of YAO film.

\section{Confirmation of the amorphous phase grown on STO substrate (Figure S4)}

The crystal structure of the film was examined by X-ray diffraction in glancing angle mode using a $\mathrm{Cu} \mathrm{K} \alpha \mathrm{X}$-ray source (GAXRD, PANalytical, X'pert Pro). The incidence angle, scan step size and time per step during the GAXRD measurement were $0.4^{\circ}, 0.01^{\circ}$ and $0.5 \mathrm{~s}$, respectively. $\mathrm{LAO}(16.5 \mathrm{~nm}), \mathrm{Al}_{2} \mathrm{O}_{3}(13.4 \mathrm{~nm})$ and stoichiometric-YAO $(12.6 \mathrm{~nm})$ films grown on STO substrate were investigated for the analysis of the phase. No peaks were observed from all films grown on STO substrate as shown in Fig. S4, which indicates that the grown films are amorphous. 


\section{Angle-resolved X-ray photoelectron spectroscopy (Figure S5)}

The illustration of the angle-resolved XPS analysis with 2.5 nm-thick $\mathrm{Al}_{2} \mathrm{O}_{3} / \mathrm{STO}$ heterostructure was described in Fig. S5. The analysis sampling depth changes as a function of the photoelectron take-off angle. The photoelectron take-off angle $(\Theta)$ is defined as the angle between the sample surface and detector, thus the analysis becomes more surface sensitive with decreasing take-off angle. The normal signal $\left(\Theta=90^{\circ}\right)$ from the bare STO substrate was used for a clear comparison in Fig. 5. The signal of $\mathrm{Ti}^{3+}$ relative to the $\mathrm{Ti}^{4+}$ main line increases as the photoelectron take-off angle decreases in $\mathrm{Al}_{2} \mathrm{O}_{3} / \mathrm{STO}$ heterostructure. This indicates that the electrons generated by oxygen vacancies are localized at the STO surface region as a 2-DEG (within $\sim 2 \mathrm{~nm}$ from the interface, not surface of the $2.5 \mathrm{~nm}$-thick $\mathrm{Al}_{2} \mathrm{O}_{3}$ ), which is smaller than the electron escape depth $(\sim 5 \mathrm{~nm})$. The electron escape depth $(\sim 5 \mathrm{~nm})$ was estimated experimentally. The Ti $3 \mathrm{~d}$ peak was not detected with a 6-nm thick film grown on a STO substrate, however, very weak Ti $3 \mathrm{~d}$ peak was appeared after an etching of the oxide surface with $1 \mathrm{~nm}$-depth, thus the maximum electron escape depth was expected to be $\sim 5 \mathrm{~nm}$. The intensity of $\mathrm{Ti}^{3+}$ is very weak because the carrier density of $\mathrm{Al}_{2} \mathrm{O}_{3} / \mathrm{STO}$ heterosture $\left(3 \times 10^{12} / \mathrm{cm}^{2}\right)$ is lower over 1-order of magnitude than any other reports using PLD $\left(\sim 10^{14} / \mathrm{cm}^{2}\right)$. The density of $3 \times 10^{12} / \mathrm{cm}^{2}$ corresponds to $0.5 \%$ of number of Ti atoms in 1 monolayer of STO, which makes low intensity of $\mathrm{Ti}^{3+}$ respect to $\mathrm{Ti}^{4+}$. 


\section{Role of TMA precursor and pre-grown $\mathrm{LAO}$ and $\mathrm{Al}_{2} \mathrm{O}_{3}$ layers (Figure $\mathrm{S6}$ )}

The tri-methyl aluminum $\left[\mathrm{Al}\left(\mathrm{CH}_{3}\right)_{3}\right.$, (TMA)], TMA molecules were introduced on the surface of $\mathrm{Y}_{2} \mathrm{O}_{3} / \mathrm{STO}$ heterostructure at $300{ }^{\circ} \mathrm{C}$ in order to confirm that TMA molecules can induce the redox reaction of STO. It should be noted that the interface of $\mathrm{Y}_{2} \mathrm{O}_{3} / \mathrm{STO}$ heterostructure is insulating as shown in Fig. 3 (b). This experiment was progressed with an identical ALD process of $\mathrm{LAO}$ or $\mathrm{Al}_{2} \mathrm{O}_{3}$ except that the valve for water injection was closed during the experiment, so that the total process time was preserved. However, the STO substrate keep insulating property $\left(\mathrm{R}_{\mathrm{s}}>10^{9} \Omega /\right.$ sq.) after the introducing of TMA molecules (55 cycles, which is much longer than the critical cycle $\sim 15$ cycles) on bare STO substrate, and also on $\mathrm{Y}_{2} \mathrm{O}_{3} / \mathrm{STO}$ heterostructure as shown Fig. S6 (a). The repetitive pulse (55 cycles) of TMA precursor cannot induce the reduction of STO substrate by itself, and also on $\mathrm{Y}_{2} \mathrm{O}_{3}$ layers grown on STO substrate irrespective of $\mathrm{Y}_{2} \mathrm{O}_{3}$ film thickness, which means that the redox reaction of STO cannot be progressed until when LAO, YAO and $\mathrm{Al}_{2} \mathrm{O}_{3}$ films are thicker than those critical thicknesses. There still exists required critical thickness of $\mathrm{LAO}$ and $\mathrm{Al}_{2} \mathrm{O}_{3}$ layers when those layers were grown on top of $\mathrm{Y}_{2} \mathrm{O}_{3}$ layer (4.7 nm-thick) to create 2-DEG, which emphasizes the important role of pre-grown $\mathrm{LAO}$ and $\mathrm{Al}_{2} \mathrm{O}_{3}$ layers (Fig. S6 (b)). $\mathrm{LAO}$ and $\mathrm{Al}_{2} \mathrm{O}_{3}$ layers (thicker than the critical thickness) are necessary for the redox reaction even on $\mathrm{Y}_{2} \mathrm{O}_{3} / \mathrm{STO}$ heterostructure, thereby it constitutes the circumstance to overcome the energy barrier, so that 
the reduction of STO can occur during the TMA pulse. We claimed that $\mathrm{Al}_{2} \mathrm{O}_{3}(>1.2 \mathrm{~nm})$ acts as a catalyst for the reaction, thus the redox reaction of STO substrate can occur when the TMA molecules are introduced.

\section{Influence of the growth temperature (Figure S7)}

The influence of ALD growth temperature on the conductivity of LAO/STO heterostructure was investigated in order to confirm that the reaction is governed by kinetics. The density of carriers decreased drastically with decreasing growth temperature, which suggests that the reaction is limited by kinetics.

\section{Mobility of LAO/STO at the low temperature (down to $30 \mathrm{~K}$ ). (Figure S8)}

The mobility of LAO/STO heterostructue was measured at the low temperature down to $30 \mathrm{~K}$. The measuring temperature was controlled by means of liquid helium, which allowed the lowest temperature of the stage down to $30 \mathrm{~K}$. The mobility of LAO/STO hetereostructure was further increased with decreasing temperature down to $30 \mathrm{~K}$.

\section{Confirm of ohmic contact (Figure S9)}


In order to confirm the contact properties, I-V measurement was performed with the two Au contacts at the corners using KEITHLEY 2400 sourcemeter. The linearity of I-V curve demonstrates that ohmic contacts were made between two Au contacts as shown in Fig. S8.

\section{Stability of 2-DEG in the heterostructure}

The sheet resistance of the LAO/STO heterostructure was increased by $>10^{3}$ in 8 months (in atmosphere at room temperature), from the fabrication of the heterostructure. However, the $\mathrm{LAO} / \mathrm{Y}_{2} \mathrm{O}_{3} / \mathrm{STO}$ heterostructure kept conducting channel for much longer period than that of the LAO/STO, i. e., the sheet resistance of the $\mathrm{LAO} / \mathrm{Y}_{2} \mathrm{O}_{3} / \mathrm{STO}$ heterostructure was increased by just $10 \%$ in 8 months (in atmosphere at room temperature), from the fabrication of the heterostructure. More research is necessary for the understanding of the retention time. 

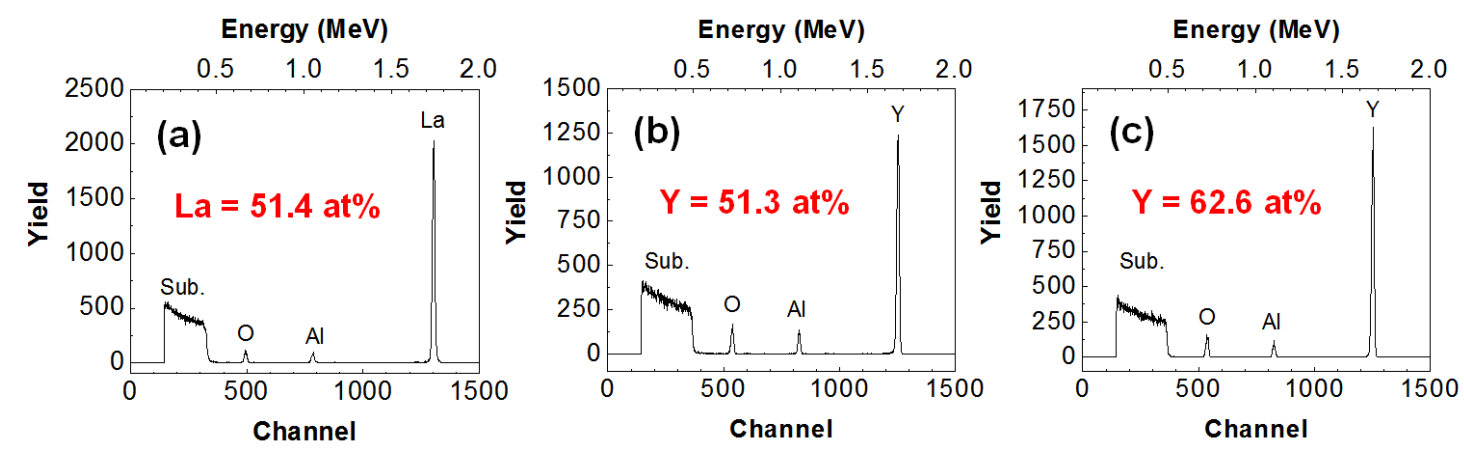

Figure S1 The composition of (a) LAO film (17 nm-thick) and YAO (18 nm) films with cycle ratios (Y:Al) of (b) 2:1 and (c) 4:1, evaluated by Rutherford back-scattering spectroscopy (RBS) using a $2 \mathrm{MeV} \mathrm{He}{ }^{2+}$ beam. The estimated atomic ratio of $\mathrm{La} /[\mathrm{La}+\mathrm{Al}]$ in the $\mathrm{LAO}$ film was $51.4 \%$, which indicates the grown film is very close to stoichiometry The estimated atomic ratios of $\mathrm{Y} /[\mathrm{Y}+\mathrm{Al}]$ in $\mathrm{YAO}$ films were 51.3 and $62.6 \%$ with cycle ratios of 2:1 and 4:1, respectively. 

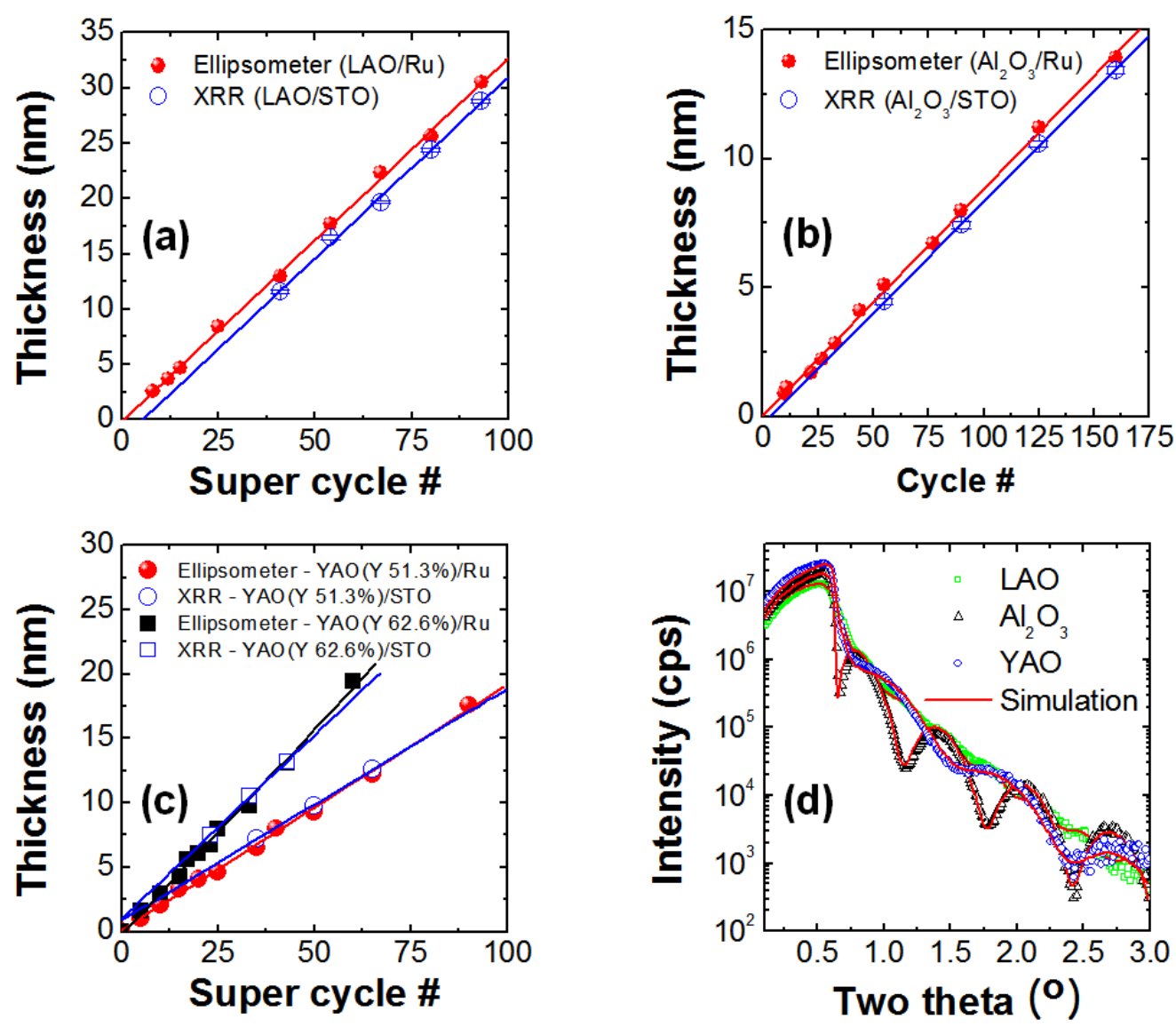

Figure $\mathrm{S} 2$ The thickness of (a) $\mathrm{LAO}$, (b) $\mathrm{Al}_{2} \mathrm{O}_{3}$ and (c) YAO films grown on an STO substrate estimated by $\mathrm{X}$-ray reflectivity measurement. Films were grown on $\mathrm{Ru}$ substrates simultaneously and the thickness was measured by ellipsometry to confirm the linear growth behavior depends on the deposition cycle number. (d) Representative simulation results of LAO, $\mathrm{Al}_{2} \mathrm{O}_{3}$ and $\mathrm{YAO}$ films grown on the $\mathrm{STO}$ substrate. 

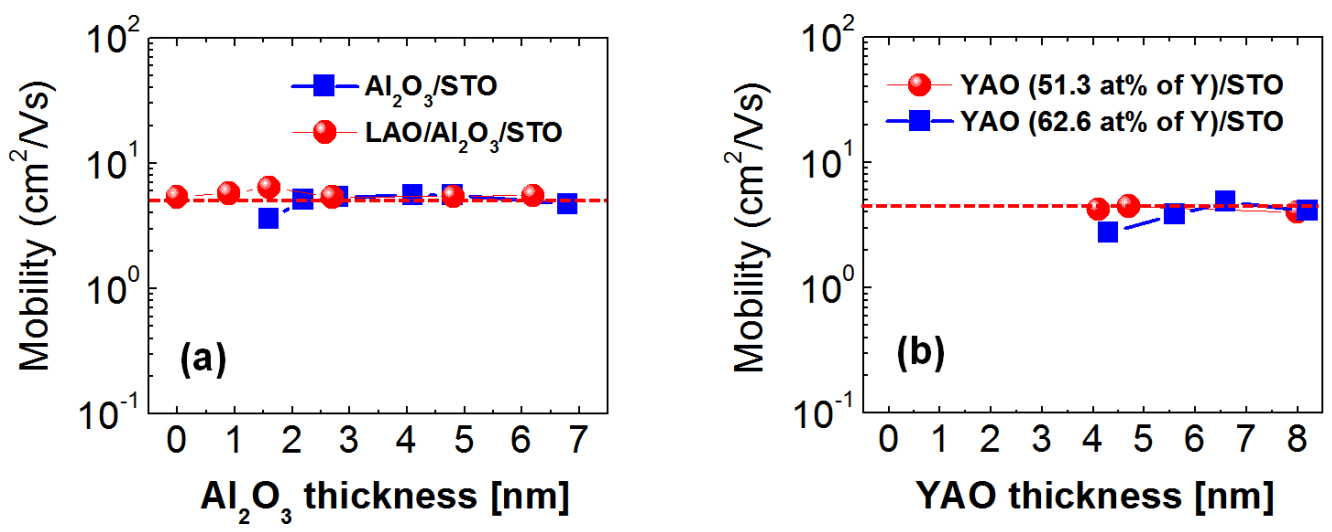

Figure $\mathrm{S} 3$ (a) The mobility of $\mathrm{Al}_{2} \mathrm{O}_{3} / \mathrm{STO}$ and $\mathrm{LAO} / \mathrm{Al}_{2} \mathrm{O}_{3} / \mathrm{STO}$ heterostructures depend on the $\mathrm{Al}_{2} \mathrm{O}_{3}$ film thickness. $6 \mathrm{~nm}$-thick LAO films were grown on top of $\mathrm{Al}_{2} \mathrm{O}_{3}$ films to fabricate $\mathrm{LAO} / \mathrm{Al}_{2} \mathrm{O}_{3} / \mathrm{STO}$ heterostructures. (b) The mobility of stoichiometric (51.3\% of Y) YAO/STO and Y-rich (62.6\% of Y) YAO/STO heterostructures as a function of YAO film thickness. YAO films were grown by ALD using cycle ratios of 2:1 (Y:Al) and 4:1, respectively. 


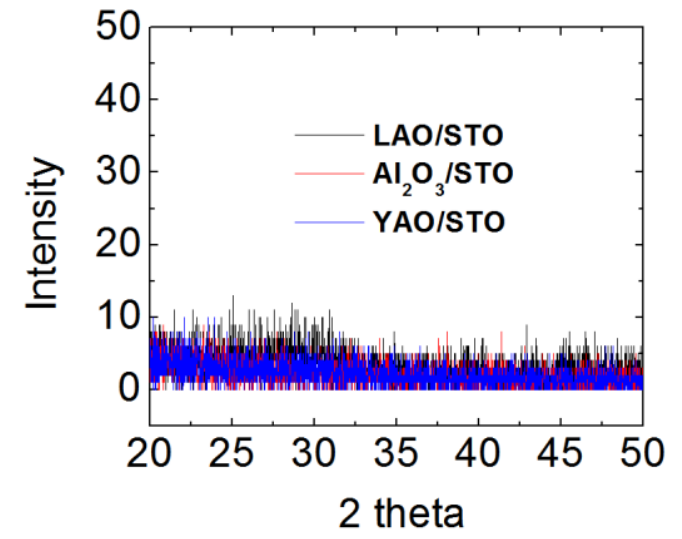

Figure S4 Glancing angle X-ray diffraction spectra of LAO/STO, $\mathrm{Al}_{2} \mathrm{O}_{3} / \mathrm{STO}$ and $\mathrm{YAO}(51.3 \%$ of Y)/STO heterostructures showing that amorphous films were grown on the STO substrates. 


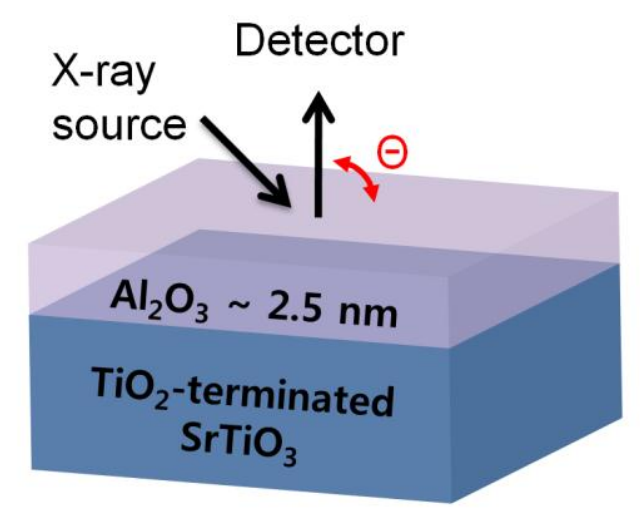

Figure S5 The illustration of the angle-resolved XPS analysis with a $2.5 \mathrm{~nm}$-thick $\mathrm{Al}_{2} \mathrm{O}_{3} / \mathrm{STO}$

heterostructure. The analysis sampling depth changes as a function of the photoelectron take-off angle. The photoelectron take-off angle $(\Theta)$ is defined as the angle between the sample surface and detector. 

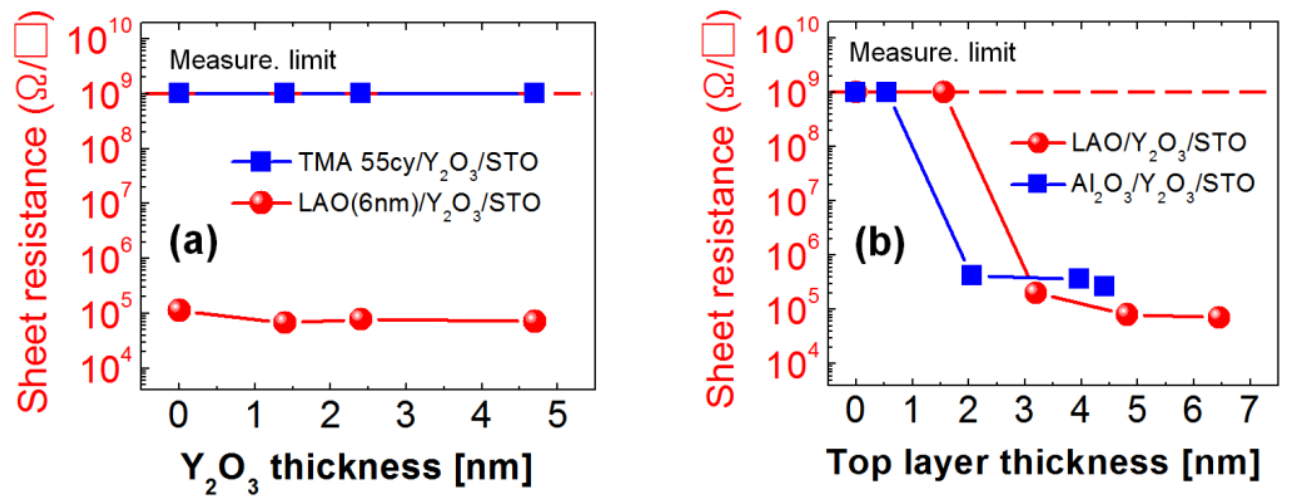

Figure S6 (a) Repetitive pulses of TMA (55 cycles) on $\mathrm{Y}_{2} \mathrm{O}_{3} / \mathrm{STO}$ heterostructure depend on the $\mathrm{Y}_{2} \mathrm{O}_{3}$ film thickness without introducing an oxygen source $\left(\mathrm{H}_{2} \mathrm{O}\right)$, which did not generate the carriers. However, the carriers were generated by means of following the deposition of a $6 \mathrm{~nm}$ thick LAO layer on top of the $\mathrm{Y}_{2} \mathrm{O}_{3} / \mathrm{STO}$ heterostructure. (b) A required critical thickness of LAO and $\mathrm{Al}_{2} \mathrm{O}_{3}$ layers grown on top of the $\mathrm{Y}_{2} \mathrm{O}_{3}$ layer (4.7 nm-thick) to create 2-DEG, which underlines the important role of $\mathrm{LAO}$ and $\mathrm{Al}_{2} \mathrm{O}_{3}$ layers. 


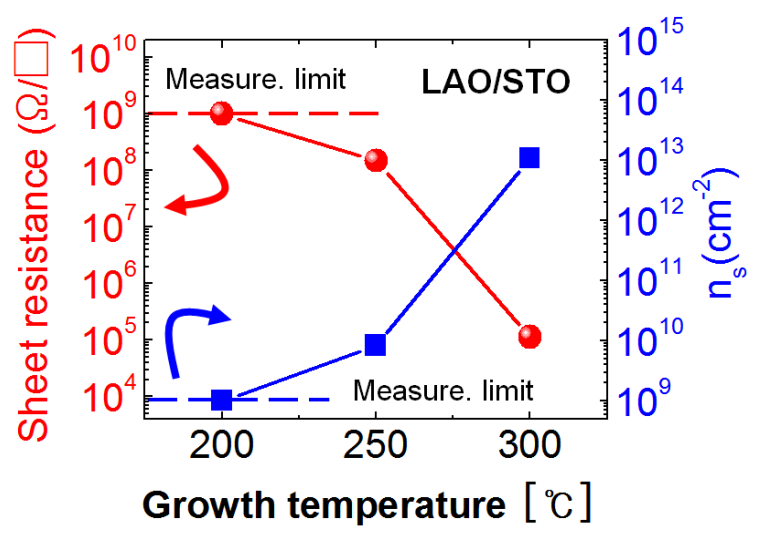

Figure S7 The influence of ALD growth temperature on the conductivity of LAO/STO heterostructure. The density of carriers decreased drastically with decreasing growth temperature. 


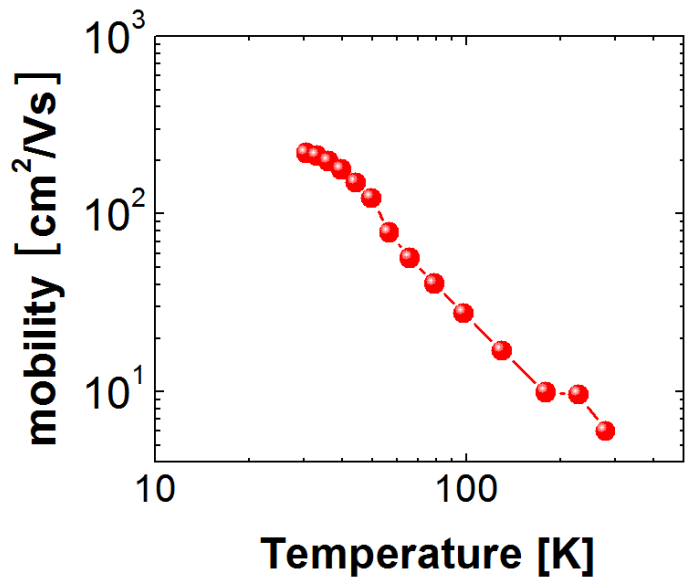

Figure S8 The mobility of LAO/STO heterostructure at the low temperature (down to $30 \mathrm{~K}$ ). 


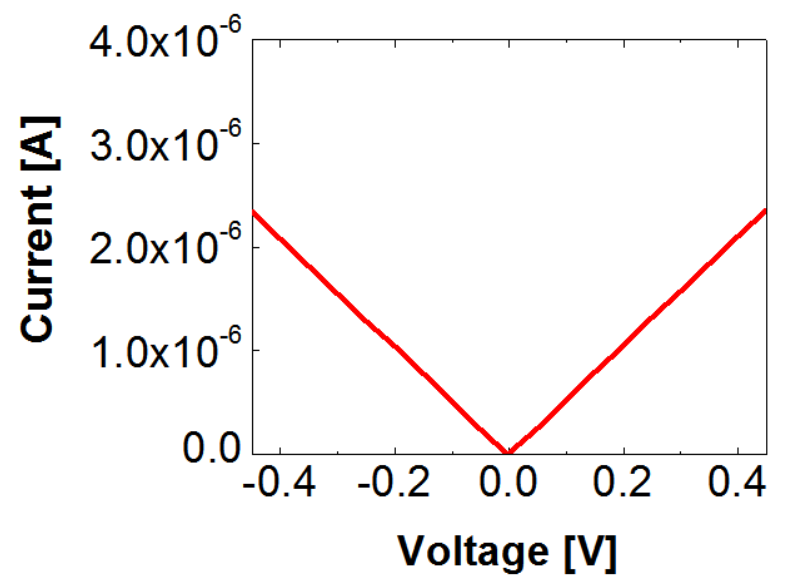

Figure S9 Ohmic I-V behavior between two Au electrodes using KEITHLEY 2400 sourcemeter. 